\title{
Pain care for patients with epidermolysis bullosa: best care practice guidelines
}

\author{
Kenneth R Goldschneider ${ }^{1 *}$, Julie Good ${ }^{2}$, Emily Harrop ${ }^{3}$, Christina Liossi ${ }^{4,5}$, Anne Lynch-Jordan ${ }^{6}$, Anna E Martinez
} Lynne G Maxwell ${ }^{8}$ and Danette Stanko-Lopp ${ }^{9}$

\begin{abstract}
Background: Inherited epidermolysis bullosa (EB) comprises a group of rare disorders that have multi-system effects and patients present with a number of both acute and chronic pain care needs. Effects on quality of life are substantial. Pain and itching are burdensome daily problems. Experience with, and knowledge of, the best pain and itch care for these patients is minimal. Evidence-based best care practice guidelines are needed to establish a base of knowledge and practice for practitioners of many disciplines to improve the quality of life for both adult and pediatric patients with EB.

Methods: The process was begun at the request of Dystrophic Epidermolysis Bullosa Research Association International (DEBRA International), an organization dedicated to improvement of care, research and dissemination of knowledge for EB patients worldwide. An international panel of experts in pain and palliative care who have extensive experience caring for patients with EB was assembled. Literature was reviewed and systematically evaluated. For areas of care without direct evidence, clinically relevant literature was assessed, and rounds of consensus building were conducted. The process involved a face-to-face consensus meeting that involved a family representative and methodologist, as well as the panel of clinical experts. During development, EB family input was obtained and the document was reviewed by a wide variety of experts representing several disciplines related to the care of patients with EB.
\end{abstract}

Results: The first evidence-based care guidelines for the care of pain in EB were produced. The guidelines are clinically relevant for care of patients of all subtypes and ages, and apply to practitioners of all disciplines involved in the care of patients with EB. When the evidence suggests that the diagnosis or treatment of painful conditions differs between adults and children, it will be so noted.

Conclusions: Evidence-based care guidelines are a means of standardizing optimal care for EB patients, whose disease is often times horrific in its effects on quality of life, and whose care is resource-intensive and difficult. The guideline development process also highlighted areas for research in order to improve further the evidence base for future care.

Keywords: Epidermolysis bullosa, Pain, Practice guidelines, RDEB, DEBRA, Acute pain, Chronic pain, Recessive dystrophic epidermolysis bullosa, Dystrophic Epidermolysis Bullosa Research Association International

\section{Background}

Inherited epidermolysis bullosa (EB) comprises a group of rare disorders, generally thought of as skin diseases. However, EB has multi-system effects and patients present with a number of both acute and chronic pain care needs [1]. Effects on quality of life are substantial [2,3]. Due to its low prevalence, expertise in pain care for patients with this disease is often restricted to a few specialized care centers.

\footnotetext{
* Correspondence: Kenneth.goldschneider@cchmc.org

'Pain Management Center, Department of Anesthesiology, Cincinnati Children's Hospital Medical Center, Cincinnati, Ohio, USA

Full list of author information is available at the end of the article
}

Even then, evidence-based pain care is limited by a near absence of scientific literature specific to EB. This set of guidelines was requested by Dystrophic Epidermolysis Bullosa Research Association International (DEBRA International) to help standardize the approach to pain care for both adult and pediatric patients with EB in all parts of the world. Consequently, a group of clinical pain care experts from a few countries have come together to lend their experience to the limited scientific literature to create these guidelines.

The present guidelines on pain care for patients with $\mathrm{EB}$ are based on a review and synthesis of the available 
literature, guided by expert consensus and thoughtful application of theory. The guidelines are divided into four topics: psychological treatment of pain and pruritus, acute pain, chronic and recurrent pain, and special topics. The Psychological and Integrative Treatments section leads off because the information it contains applies to all the topics that follow. The Acute Pain section focuses on postoperative pain. The Chronic and Recurrent Pain section includes dressing changes, baths, skin pain and joint and other body pains. The Special Topics section includes pain care in infants with EB and pain care at the end of life. While not pain per se, itching is a major source of discomfort [4] and is also discussed.

The aim of the guidelines is to provide the user with information on pain care for children and adults with EB. These guidelines can be applied to all patients diagnosed with hereditary forms of EB. Patients with acquired forms are not included in the guidelines. The guidelines contain two types of guidance. Recommendations are graded and highlighted in text boxes at the end of the manuscript. Good Practice Points are located at the end of each topical section and summarize concepts and best practices, based on the clinical experience of the guidelines development group.

The daily routine of many patients with severe forms of EB will have a number of painful events, each of which may suggest the need for intervention. However, addressing each one pharmacologically may lead to a level of sedation that prevents a meaningful level of productivity. It is important to discuss the needs of the patient and the options for caring for those needs with the patient and family. Together, the patient, family and practitioner can transform the guidelines into an individualized care plan. It is to be expected that each patient's needs will be dynamic; periodic review of the needs and goals will optimize care at each step of the patient's life.

Of note, the term 'EB' will be used throughout the text. However, four major types of EB are known and are categorized as Simplex (EBS), Junctional (JEB), dystrophic types (DEB) and Kindler Syndrome. A recent consensus statement was released that reclassified the subtypes further based on anatomic location within the skin and pattern of involvement, and discouraged the use of eponyms (with the exception of Kindler Syndrome). EBS is sub-typed as EBS suprabasal and EBS basal, JEB as JEB generalized and JEB localized, DEB as Recessive DEB and Dominant DEB (RDEB and DDEB, respectively) [5]. Additionally, there are at least 18 genes associated with the different types of EB [5]. The proposed new classification does not address the relation to painful conditions, and, thus, the four major types will be referenced throughout the guidelines. There is a wide range of severity within the types. EBS is usually due to autosomal dominant mutations in keratin 5 or 14 or in plectin and is often of milder severity. JEB can result from mutations in any of six different basement membrane components, is inherited as an autosomal recessive disorder, and can range from mild to fatal early in life. DEB can be in a mild dominant form (DDEB) or a more severe recessive one (RDEB), both due to mutations in collagen 7 . The recommendations that follow are intended to be generally applicable to all patients with EB who experience pain. The pain conditions vary in prevalence among the types of $\mathrm{EB}$, and readers will find relevant guidelines to apply in the care of the particular pain problems they and their patients face. Resources (for example, particular medications and formulations, trained medical, nursing and therapy personnel) will vary by location, and practitioners and families will, therefore, need to adapt the recommendations based on what is available in their locale. DEBRA International [6] is an optimal facilitating organization that can aid implementation of the guidelines by way of providing information, support and means of contacting expert care providers.

\section{Methods}

In 2011, a multidisciplinary working group formed to develop best care practice guidelines for pain associated with EB. The group comprised representatives from nursing, medicine and psychology who were expert in the clinical care of patients with EB. Guidelines topics and subtopics were chosen by the multidisciplinary group with input from outside clinicians, based on issues presented in the literature, seen clinically and raised for discussion at DEBRA International Congress meetings. Individuals or small groups were assigned to the various subtopics. After relevant literature was reviewed, preliminary recommendations for each subsection were made. Recommendations were circulated by email among the entire panel of experts for review and input/feedback was incorporated. Initial citations were added or removed as required for accuracy and appropriateness, and criticism made of areas of weakness. Thus, the group formed the first iteration of expert consensus. The revised recommendations were recirculated to the group for review, to establish consensus more firmly. A panel of outside reviewers, comprising both clinicians and patients/families, then reviewed the document for comprehensibility, omissions and applicability.

Following external review (see Acknowledgements for reviewers), funding became available and a subsequent systematic evidence review was conducted by a trained methodologist (author DSL). Clinical questions and the systematic search strategy were developed, based on the guideline topics and subtopics from the working group. The population of interest comprises patients with pain 
who have any variant of EB. The interventions included, but were not limited to, pharmacological, holistic, psychological, psychical therapy and/or environmental interventions. Outcomes of interest were improvement in symptom control (for example, pain, itch) and level of function.

Systematic literature searches were conducted using MedLine, CINAHL, PsycInfo and The Cochrane Library. Search terms for 'epidermolysis bullosa' and 'pain', 'regional anesthesia', or 'nerve block' were used as medical subject headings and/or keywords in all databases. The search was only limited to articles published in English. No other restrictions, limits or filters were used. Publication dates were not restricted for any topic or subtopic, as the diagnosis is rare and there were few studies of higher level, directly-related evidence (that is, systematic reviews, meta-analyses, randomized controlled trials). Reference lists were searched to identify studies. Studies submitted by the working group and used in the initial consensus processes were also reviewed. The most recent systematic search for pediatric acute, chronic, or recurrent pain management in EB patients was conducted in December 2011.

Citations from the evidence searches were reviewed by title and abstract for potential inclusion, regardless of study design $(n=1,061)$. Evidence related to the clinical questions from systematic reviews, meta-analyses and RCTs as well as observational studies, case reports and expert opinion articles were reviewed (see Figure 1). A total of 57 references were found and evaluated that were specific to the cross match of EB and the painrelated keywords (see above), of which only 8 were included into specific recommendations. The rationale for including and excluding these references is found in Table 1 and in Additional file 1.
All included articles were critically appraised using evidence appraisal forms from the LEGEND (Let Evidence Guide Every New Decision) evidence evaluation system $[7,8]$. The methodologist assessed risk of bias in the included studies by evaluating quality for all individual studies by domain and study design. The quality levels for included studies were recorded (see Table 2). The reader will find the evidence level for each article used to directly support each recommendation noted after its citation in the Reference section of the Summary of recommendations (Table 3). Age specificity of each recommendation is also noted. Data were collected on descriptive characteristics of patients, characteristics of the pain management interventions, and associated outcomes of reported pain management interventions. Using the Grade for the Body of Evidence tool in the LEGEND system [7] provided objective criteria for evaluating evidence related to each recommendation (see Table 4).

Given the paucity of data for statistical analysis, it was deemed appropriate to conduct a face-to-face consensus meeting on 4, 5 May 2012 in Cincinnati, OH. The LEGEND tool for Judging the Strength of a Recommendation (see Table 4) was used as a guide for finalizing recommendation statements by discussing the body of evidence and discussing safety/harm and other dimensions [7]. The overall GRADE (A, B, C, D) for each recommendation statement was then determined, based on this process and the established criteria for GRADE $[9,10]$.

\section{Updating procedure}

The guidelines will be updated every three years after the first version. If new relevant evidence is detected before the update, the information will be published on the

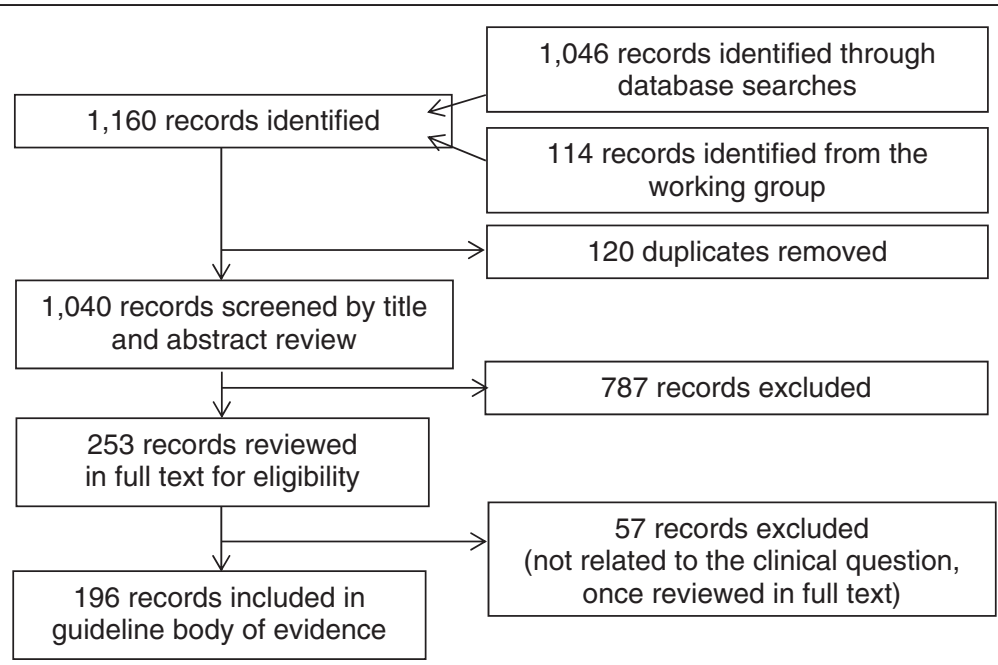

Figure 1 Flow of information through the evidence evaluation process. 
Table 1 EB-specific articles used in producing recommendations

\begin{tabular}{|c|c|c|c|c|}
\hline Study citation & Study type & Population (setting, patients) & Intervention/Comparison groups & Outcomes \\
\hline Chiu 1999 [68] & Case report & $\begin{array}{l}\text { Country: Canada Setting: Children's } \\
\text { Hospital Age: } 11 \text { years Gender: } \\
\text { Male Patient with Severe JEB }\end{array}$ & $\begin{array}{l}\text { Amitryptiline ( } 25 \mathrm{mg} \text { at night) was } \\
\text { prescribed and patient started on a } \\
\text { program of cognitive behavioral } \\
\text { training (hypnotic imagery, distraction). } \\
\text { Oral midazolam ( } 7.5 \mathrm{mg} \text { ) was initiated } \\
20 \text { minutes prior to bath or dressing } \\
\text { change }\end{array}$ & Pain management \\
\hline $\begin{array}{l}\text { Goldschneider } \\
2010[41,42]\end{array}$ & Review articles & $\begin{array}{l}\text { Country: United States Setting: } \\
\text { Children's Hospital Patients } \\
\text { with EB }\end{array}$ & Pain management and prevention & Pain management \\
\hline Herod 2002 [44] & Review article & $\begin{array}{l}\text { Country: England (London) Setting: } \\
\text { Children's Hospital Patients with EB }\end{array}$ & General pain management & Pain management \\
\hline Mellerio 2007 [152] & Review article & $\begin{array}{l}\text { Country: United States, England, } \\
\text { Chile Setting: Hospital Patients } \\
\text { with EB }\end{array}$ & Medical management & General pain management \\
\hline Saroyan 2009 [156] & Case report & $\begin{array}{l}\text { Country: United States Setting: } \\
\text { Hospital Female infant with EBS, } \\
\text { severe, Dowling-Meara subtype }\end{array}$ & $\begin{array}{l}\text { Use of IV ketamine given orally Oral } \\
\text { administration of IV ketamine ( } 10 \mathrm{mg} / \mathrm{mL} \text {, } \\
\text { Monarch Pharmaceuticals) at a starting } \\
\text { dose of } 0.5 \mathrm{mg}(0.125 \mathrm{mg} / \mathrm{kg} / \text { dose) Over } \\
\text { four days, the dose was titrated to } 3 \mathrm{mg} \\
\text { ( } 0.75 \mathrm{mg} / \mathrm{kg} / \text { dose) in response to observed } \\
\text { effect }\end{array}$ & $\begin{array}{l}\text { Achieve analgesia during } \\
\text { painful dressing changes }\end{array}$ \\
\hline $\begin{array}{l}\text { van Scheppingen } \\
2008[4]\end{array}$ & $\begin{array}{l}\text { Qualitative study } \\
\text { (Interviews) }\end{array}$ & $\begin{array}{l}\text { Country: Netherlands Setting: } \\
\text { Center for Blistering Diseases } \\
\text { Age: } 6 \text { to } 18 \text { years Children } \\
\text { with different (sub)types of EB) }\end{array}$ & $\begin{array}{l}\text { Interviews conducted at homes or in hospital } \\
\text { Questions explored were: (i) What problems } \\
\text { do children with EB actually experience as } \\
\text { being the most difficult? (ii) What is the } \\
\text { impact of these problems on their daily life? } \\
\text { (iii) Are there differences in experiences } \\
\text { between mildly and severely affected } \\
\text { children? }\end{array}$ & $\begin{array}{l}\text { Themes of pain for severe } \\
\text { disease (generalized blistering } \\
\text { with motion impairment) and } \\
\text { for mild disease (localized } \\
\text { blistering or generalized } \\
\text { blistering without motion } \\
\text { impairment). }\end{array}$ \\
\hline Watterson 2004 [74] & Case report & $\begin{array}{l}\text { Country: United States Setting: } \\
\text { Hospital Children with EB using } \\
\text { peripheral opioids }\end{array}$ & $\begin{array}{l}\text { Topical morphine gel applied to the most } \\
\text { painful areas of skin at that time for each } \\
\text { child }\end{array}$ & Pain scores \\
\hline
\end{tabular}

EB, epidermolysis bullosa, EBS, epidermolysis bullosa simples; JEB, junctional epidermolysis bullosa.

web page for DEBRA International that is dedicated to clinical the Pain guidelines [11].

\section{Results and discussion}

\section{Psychological and integrative approaches} Introduction

A biopsychosocial approach emphasizing medical, psychological and physical therapies for pain management has been suggested to be the most useful for adults and

\section{Table 2 Evidence levels [8]}

\begin{tabular}{ll}
\hline Quality level & Definition \\
\hline $1 a^{a}$ or $1 b^{a}$ & $\begin{array}{l}\text { Systematic review, meta-analysis, } \\
\text { or meta-synthesis of multiple studies }\end{array}$ \\
$2 a$ or $2 b$ & Best study design for domain \\
$3 a$ or $3 b$ & Fair study design for domain \\
$4 a$ or $4 b$ & Weak study design for domain \\
$5 a$ or $5 b$ & General review, expert opinion, \\
& $\begin{array}{l}\text { case report, consensus report, } \\
\text { or guideline }\end{array}$ \\
5 & Local Consensus \\
\hline$a=$ good quality study; $b=$ lesser quality study.
\end{tabular}

children with acute and chronic pain [12]. This approach has also been advocated for EB patients [3] and should be initiated from early in youth and modified with maturation. It is recommended that psychological interventions be used in conjunction with physical and pharmacologic therapies.

\section{Types of therapies}

Psychological therapies for pain management have been shown to modify pain intensity, reduce related distress, decrease pain-related functional disability and improve pain coping. Painful experiences amenable to treatment include acute pain related to procedures (for example, whirlpool treatments) or medical routines (for example, bandage changes, bathing), and chronic pain conditions such as headache, abdominal pain or other disease-related conditions. Psychological therapies include cognitive behavioral therapy (CBT), hypnosis, biofeedback and relaxation training, among others. CBT focuses on changing the catastrophic thinking and negative emotions surrounding pain as well as modifying lifestyle to promote wellness behavior despite chronic pain [13]. Hypnosis is a 
Table 3 Summary of recommendations

\begin{tabular}{|c|c|c|c|}
\hline Application & $\begin{array}{l}\text { Level of } \\
\text { recommendation }\end{array}$ & $\begin{array}{l}\text { Target age } \\
\text { group }\end{array}$ & Key references (evidence grade) \\
\hline \multicolumn{4}{|c|}{ A. Psychological therapies offer effective approaches to management of chronic and acute pain as well as itching. } \\
\hline $\begin{array}{l}\text { For chronic pain management use cognitive behavioral } \\
\text { therapy (CBT). }\end{array}$ & B & All & Gerik 2005 [13] (5a), Palermo 2005 [17] (5a) \\
\hline $\begin{array}{l}\text { For acute pain management, offer the patient distraction, } \\
\text { hypnosis, visualization, relaxation or other forms of CBT }\end{array}$ & B & All & Green 2005 [14] (5a), Uman 2006 [21] \\
\hline $\begin{array}{l}\text { Consider habit reversal training, and other psychological } \\
\text { techniques for management of pruritus }\end{array}$ & C & All & $\begin{array}{l}\text { Chida } 2007 \text { [29] (1a), Ehlers } 1995 \text { [32] (2b), Azrin } 1973 \text { [30] } \\
\text { (4b), Hagermark } 1995 \text { [28] (5a), Rosenbaum } 1981 \text { [31] (5a) }\end{array}$ \\
\hline
\end{tabular}

B. Postoperative pain can be handled as for other patients in the same setting, with modifications.

\begin{tabular}{|c|c|c|c|}
\hline $\begin{array}{l}\text { Basic perioperative assessment and pain treatments } \\
\text { should be used as for non-EB patients, with modification }\end{array}$ & A & All & Goldschneider 2010 [41] (5a), Goldschneider 2010b [42] (5a) \\
\hline $\begin{array}{l}\text { Transmucosal (including intranasal fentanyl and } \\
\text { transbuccal opioids) should be considered for short } \\
\text { procedures and pain of brief duration when intravenous } \\
\text { and enteral routes are unavailable }\end{array}$ & B & All & $\begin{array}{l}\text { Manjushree et al., } 2002 \text { [45] (2b); Borland et al., } 2007 \text { [46] } \\
\text { (2b); Desjardins et al., } 2000 \text { [47] (2a) }\end{array}$ \\
\hline $\begin{array}{l}\text { Perioperative opioid use must account for preoperative } \\
\text { exposure, with appropriate dose increases to account for } \\
\text { tolerance }\end{array}$ & B & All & $\begin{array}{l}\text { Hartrick } 2008 \text { [56] (1a), Mhuircheartaigh } 2009 \text { [55] (1a), } \\
\text { Viscusi } 2005 \text { [54] (2a) }\end{array}$ \\
\hline $\begin{array}{l}\text { Regional anesthesia is appropriate for pain resulting from } \\
\text { a number of major surgeries. Dressing of catheters must } \\
\text { be non-adhesive and monitored carefully }\end{array}$ & C & All & $\begin{array}{l}\text { Diwan } 2001 \text { [51] (5a), Doi } 2006 \text { [53] (5b), Englbrecht } \\
2010 \text { [52] (5a), Kelly } 1988 \text { [48] (5b), Sopchak } 1993 \text { [49] (5a), } \\
\text { Yee } 1989 \text { [50] (5a) }\end{array}$ \\
\hline
\end{tabular}

C. Skin wounds and related pain are the hallmark of EB of most subtypes. Prevention and rapid healing of wounds through activity pacing, optimal nutrition and infection control are important. A number of pharmacologic treatments are available

\begin{tabular}{|c|c|c|c|}
\hline $\begin{array}{l}\text { Maintain optimal nutrition and mobility and treat } \\
\text { infections as indicated }\end{array}$ & D & All & Denyer 2010 [57] (5a) \\
\hline Consider topical therapies for pain & C & All & $\begin{array}{l}\text { Cepeda } 2010 \text { [77] (1a), Lander } 2006 \text { [76] (1a), LeBon } 2009 \\
\text { [73] (1a), Twillman 1999 [72] (5a), Watterson } 2004 \text { [74](5a) }\end{array}$ \\
\hline $\begin{array}{l}\text { Systemic pharmacologic therapy should be adapted to } \\
\text { treat both acute and chronic forms of skin pain }\end{array}$ & B & All & $\begin{array}{l}\text { Noble } 2010 \text { [59] (1a), Moore, } 2011 \text { [ 67] (1a), Nicholson } \\
2009 \text { [65] (1a) }\end{array}$ \\
\hline $\begin{array}{l}\text { Monitor potential long-term complications of chronically } \\
\text { administered medications }\end{array}$ & C & Pediatric & $\begin{array}{l}\text { Huh } 2010 \text { [62] (4a), Camilleri } 2011 \text { [66] (5a), Chiu } 1999 \text { [68] } \\
\text { (5a), Cruciani } 2008 \text { [63] (5a), Gray } 2008 \text { [69] (5a) }\end{array}$ \\
\hline
\end{tabular}

\section{Baths and dressing changes require attention to both pain and anxiety}

Anxiolytics and analgesics should be used for procedural pain and fear. Care must be taken when combining such B All medications due to cumulative sedative effects

All Bell 2009 [85] (1a), Blonk 2010 [84] (1b), Ezike 2011 [82] (2a), Desjardins 2000 [47] (2a), Borland 2007 [46] (2b), Manjushree 2002 [45] (2b), Humphries 1997 [83] (2b), Wolfe 2010 [81] (5a), Ugur 2009 [86] (5a)

Cognitive behavioral techniques should be implemented as the child becomes old enough to use them Green 2005 [14] (5a); Gerik 2005 [13] (5a), Palermo 2005 effectively. Specifically, distraction should be used for younger children

Environmental measures such as adding salt to the water to make it isotonic and keeping the room warm are [17] (5a) recommended

E. EB affects the gastrointestinal tract in its entirety. Pain from ulcerative lesions responds to topical therapy. GERD and esophageal strictures have nutritional as well as comfort implications and should be addressed promptly when found. Maintaining good bowel habits and reducing iatrogenic causes of constipation are crucial.

Topical treatments are recommended for oral and perianal pain

Therapy should be directed to manage gastroesophageal reflux and esophageal strictures using standard treatments

Constipation should be addressed nutritionally, with hydration and addition of fiber in the diet to keep stool soft, by minimizing medication-induced dysmotility and with stool softeners
Ergun 1992 [98] (4a), Travis 1992 [97] (4b), Marini 2001 [99] (5a), Buchsel 2008 [100] (5a), Buchsel 2003 [101] (5b), Cingi 2010 [102] (2a)

Freeman 2008 [95] (4a)

Belsey 2010 [112] (1a), Freeman 2008 [98] (4a), Hanson 2006 [113] (4a) 


\section{Table 3 Summary of recommendations (Continued)}

\begin{tabular}{|c|c|c|}
\hline \multicolumn{3}{|c|}{$\begin{array}{l}\text { F. Bone pain treatment must account for factors that include nutrition, mobility, potential occult fractures and is treated by combinations of } \\
\text { nutritional, physical, pharmacologic and psychological interventions. }\end{array}$} \\
\hline $\begin{array}{l}\text { Joint pain should be treated with mechanical interventions, } \\
\text { physical therapy, CBT and surgical correction }\end{array}$ & All & $\begin{array}{l}\text { Bruckner } 2011 \text { [126] (4b), Gandrud } 2003 \text { [131] (4b), Martinez } \\
2010 \text { [125] (5a), Lacativa } 2010 \text { [127] (5a), Tilg } 2008 \text { [128] (5a), } \\
\text { Noguera } 2003 \text { [130] (5a), Falcini } 1996 \text { [132] (5a) }\end{array}$ \\
\hline Osteoporosis should be treated to reduce pain in EB & All & Levis 2012 [129] (1a), Martinez 2010 [125] (5a) \\
\hline Back pain should be addressed with standard & All & Chou, et al., 2007 [133] (5a) \\
\hline
\end{tabular}
multi-disciplinary care

\section{G. Corneal abrasions are common in EB, prevention and supportive care are appropriate}

Care should include general supportive and analgesic care, C A All Watson, 2012 [136] (1a), Calder 2005 [138] (1a) protecting the eye from further damage, and topical therapies

H. Pain in infants is as widespread as in any other age, but unique pharmacologic, developmental and physiologic issues must be accounted for in infants with all types of EB

\begin{tabular}{|c|c|c|c|}
\hline $\begin{array}{l}\text { Assess patients as needed and prior to and after } \\
\text { interventions; health care workers should use validated } \\
\text { measures. (Grade: A) }\end{array}$ & A & Infants & $\begin{array}{l}\text { Gibbins } 2014 \text { [139] (2a) Stevens } 2014 \text { [140] (2a), Hummel } \\
2008 \text { [141] (2a), Krechel } 1995 \text { [142] (2b), Lawrence } 1993 \\
\text { [143] (2b), Manworren } 2002 \text { [144] (2a) }\end{array}$ \\
\hline $\begin{array}{l}\text { Sucrose solutions should be administered for mild to } \\
\text { moderate pain alone or as an adjunct }\end{array}$ & B & $\begin{array}{l}\text { Young } \\
\text { infants }\end{array}$ & $\begin{array}{l}\text { Harrison } 2010 \text { [150] (1a), Yamada } 2008 \text { [149] (1a) Cignacco } \\
2012 \text { [151] (2a) }\end{array}$ \\
\hline $\begin{array}{l}\text { Standard analgesics should be used in infants as in older } \\
\text { patients with careful attention to dosing and monitoring }\end{array}$ & B & Infants & Tremlett 2010 [153] (5a), MacDonald 2010 [154] (5b) \\
\hline
\end{tabular}
patients with careful attention to dosing and monitoring

I. End of Life pain care is an expected part of care for EB, which in many cases is life-limiting in nature. All basic principles of palliative care apply as they do for other terminal disease states.

\begin{tabular}{|c|c|c|c|}
\hline $\begin{array}{l}\text { Assess and manage physical, emotional and spiritual } \\
\text { suffering of the patient, while providing support for the } \\
\text { whole family }\end{array}$ & A & All & Craig 2007 [165] (5a), AAP 2000 [166] (5b), WHO [167] (5b) \\
\hline $\begin{array}{l}\text { Opioids are the cornerstone of good analgesia in this } \\
\text { setting. Opioid rotation may need to be considered to } \\
\text { improve analgesia and reduce side effects, and adjuncts } \\
\text { may need to be added }\end{array}$ & B & All & $\begin{array}{l}\text { Eisenberg } 2009 \text { [174] (1a), Quigley } 2010 \text { [172] (1a), Davies } \\
2008 \text { [61] (4a), Bruera } 1996 \text { [171] (4b), Watterson } 2005 \text { (5b) }\end{array}$ \\
\hline $\begin{array}{l}\text { Consider targeted medication for neuropathic pain when } \\
\text { pain proves refractory to conventional therapies }\end{array}$ & D & All & $\begin{array}{l}\text { Allegaert } 2010 \text { (5a), Saroyan } 2009 \text { (5a). Clements } 1982 \text { (5a), } \\
\text { Watterson } 2005 \text { [87] (5b) }\end{array}$ \\
\hline $\begin{array}{l}\text { Continuous subcutaneous infusion of combinations of } \\
\text { medication is an option when parenteral therapy is } \\
\text { needed in the terminal phase }\end{array}$ & C & All & $\begin{array}{l}\text { Reymond } 2003 \text { [178] (2b), O'Neil } 2001 \text { [176] (5a), Watterson } \\
2005 \text { [87] (5b) }\end{array}$ \\
\hline $\begin{array}{l}\text { Where needed, breakthrough medication can be given } \\
\text { transmucosally (oral or nasal) for rapid onset and avoidance }\end{array}$ & B & All & Zeppetella 2009 [182] (1a) \\
\hline
\end{tabular}

of the enteral route

J. A combination of environmental, cognitive-behavioral and pharmacologic therapies are available for use for EB-related pruritus, which can be a severe symptom of the disease.

$\begin{array}{llll}\begin{array}{l}\text { Use environmental and behavioral interventions for itch } \\ \text { control }\end{array} & \text { C } & \text { All } & \text { Nischler 2008 [183] (5b), EB Nurse Website [187] (5b) } \\ \begin{array}{l}\begin{array}{l}\text { Antihistamines are recommended and can be chosen } \\ \text { depending upon desirability of sedating effects }\end{array} \\ \begin{array}{l}\text { Gabapentin, pregabalin, TCA, SNRls and other } \\ \text { non-traditional antipruritics agents should be strongly } \\ \text { considered for itch treatment }\end{array}\end{array} \quad \text { C } & \text { All } & \text { Ahuja 2011 [188] (2b), Goutos 2010 [186] (3a) }\end{array}$

EB, epidermolysis bullosa; GERD, gastroesophageal reflux disease; SNRI, serotonin norepinephrine reuptake inhibitors; TCA, tricyclic antidepressant.

psychological state of heightened awareness and focused attention, in which critical faculties are reduced and susceptibility and receptiveness to ideas are greatly enhanced [14]. Relaxation training usually includes techniques, such as diaphragmatic breathing, muscle relaxation and visualization/imagery, that assist in adaptive coping via distraction, reduced emotional arousal and activation of the parasympathetic nervous system. While these interventions are frequently patient-focused, CBT can also include parent/family training related to behavioral management, reducing caregiver distress and enhancing environmental factors necessary for positive coping [15]. 
Table 4 Table for judging the strength of a recommendation [8]

\begin{tabular}{ll}
\hline Dimension & Definition \\
\hline $\begin{array}{l}\text { Grade of the body of evidence } \\
\text { Safety/harm (side effects and } \\
\text { risks) }\end{array}$ & High, Moderate, Low, Not Assignable \\
$\begin{array}{l}\text { Health benefit to patient } \\
\text { Burden on patient to adhere to } \\
\text { recommendation }\end{array}$ & Low, Unaficant, Moderate, Minimal \\
$\begin{array}{l}\text { Cost-effectiveness to healthcare } \\
\text { system }\end{array}$ & $\begin{array}{l}\text { Cost-effective, Inconclusive, Not } \\
\text { cost-effective }\end{array}$ \\
$\begin{array}{l}\text { Directness of the evidence for } \\
\text { this target population }\end{array}$ & $\begin{array}{l}\text { Directly relates, Some concern of } \\
\text { directness, Indirectly relates }\end{array}$ \\
$\begin{array}{l}\text { Impact on morbidity/mortality } \\
\text { or quality of life }\end{array}$ & High, Medium, Low \\
\hline
\end{tabular}

As an adjunct to relaxation training, biofeedback monitors physiological functions (for example, heart rate, muscle tension, temperature) in order to improve control of bodily processes that might ease chronic pain. Frequently, sensors are attached to the skin by adhesive, which is relatively contraindicated in EB. Clip on pulse oximeter probes can be safely used in patients with EB to track heart rate, and provide an alternative method of biofeedback.

\section{Efficacy of psychological interventions in chronic and acute pain management}

Psychological therapies have been shown to be effective in decreasing pain intensity and frequency in other pediatric chronic pain conditions $[16,17]$ with emerging evidence showing improvement in pain-related functional disability as well $[17,18]$. The addition of biofeedback to relaxation training does not necessarily result in superior pain outcomes [17]. Modest data support the use of CBT in adults with chronic pain and disability [19] (see Box 1).

\section{Box 1. Recommendations for use of cognitive behavioral therapies in EB}

1. For chronic pain management use cognitive behavioral therapy (CBT). (Grade: B)

2. For acute pain management, offer the patient distraction, hypnosis, visualization, relaxation or other forms of CBT.

(Grade: B)

3. Consider habit reversal training, and other psychological techniques for management of pruritus. (Grade: C)
Psychological interventions are useful for the management of acute pediatric pain (see Box 1) although evidence for their efficacy varies depending on the type of pain. For procedure related pain, particularly needle procedures, distraction, hypnosis and CBT are effective, evidence based interventions [20-24].

In a review of non-pharmacological treatments to reduce the distress due to acute wound care in burn patients, some evidence has been shown that healthcare provider interventions (massage and maximizing patient control and predictability), child interventions (for example, virtual reality gaming [25] and therapist coaching of stress management techniques [26]) are beneficial.

For postoperative pain, there is insufficient evidence for the efficacy of most psychological interventions, but preparation, guided imagery and CBT are promising [27].

\section{Psychological interventions for itch}

Patients with EB may experience severe itch, which not only intensifies their suffering but can also be a source of social embarrassment secondary to the appearance of the excoriated skin and the preoccupation with scratching in social situations. Beyond this, damage of the integrity of the skin can create a portal of entry for systemic infections. Regardless of the underlying cause, itch evokes the behavior of scratching that increases inflammation and stimulates nerve fibers, leading to more itching and scratching [28]. Perpetuation of the itchscratch cycle alters the integrity of skin leading to barrier damage. Scratching also causes undesirable changes in skin, such as lichenification and prurigo nodule formation. Successful treatment of itch requires interruption of this cycle. Non-pharmacological treatments, such as CBT, hypnosis, meditation, prayer, biofeedback and eye movement desensitization and reprocessing (EMDR), have been used with some success in both adults and children with conditions such as atopic dermatitis [29]. Habit reversal is a specific behavioral intervention whereby habitual behaviors are brought into conscious awareness and specific behavioral techniques are developed as a competing response to the urge to itch [30,31] (see Box 1). In practice, this technique is frequently combined with $\mathrm{CBT}$ and relaxation as part of a treatment package applicable to patients of all ages $[29,32]$.

\section{Integrative medicine therapies}

Complementary and alternative medicine (CAM) practices constitute therapies that are often requested by patients and families for a variety of chronic pain conditions. This class of treatments includes, but is not limited to: acupuncture, meditation, massage, herbal preparations, yoga and chiropractic work. The evidence for therapies such as acupuncture [33], music 
therapy [34], chiropractic care, or yoga [35] is modest in the pediatric and adult pain populations, with no specific studies in EB. Prima facie evidence would suggest that massage and chiropractic interventions might be harmful given the skin fragility and the osteopenia that is often seen in EB. With regard to herbal supplementation, one of the chief side effects for a number of these preparations is bleeding, although the evidence is not clear [36]. Thus, this treatment may be contraindicated in patients having surgery, open wounds or a history of gastrointestinal tract bleeding. The active ingredients in the herbal preparations may also have interactions with any other prescribed medication; attention to potential drug-drug interactions should be considered.

Good practice points Assessment of the suitability of psychological therapies for EB patients experiencing chronic and acute pain should always take into account developmental issues including age, cognitive level and psychopathology [37]. Include parents in behavioral pain management interventions [38] for children and adolescents.

\section{Acute pain care: postoperative pain management Introduction}

As a multisystem disorder, EB causes a variety of disruptions to body systems that are amenable to surgical intervention. While there are no controlled trials of postoperative pain therapies in $\mathrm{EB}$, general principles of pain care apply.

\section{Assessment}

As for all patients, pain should be regularly assessed, and then reassessed after intervention to evaluate analgesic efficacy and detect side effects. Numeric rating scales have been shown to be effective for children of a developmental level above eight years who can verbalize their pain scores as well as for adults. Pain assessment in younger or nonverbal patients can be completed using the Face Legs Arms Cry Consolability (FLACC) and Children's Hospital of Eastern Ontario Pain Scale (CHEOPS) $[39,40]$ augmented by reports of parents or other close family care-givers.

\section{Systemic therapies}

Analgesic treatment starts before and during surgery and includes the use of opioids, non-steroidal antiinflammatory drugs, acetaminophen and, when appropriate for the type of surgery, regional anesthesia $[41,42]$. Patient controlled analgesia (PCA) technology is a safe and useful way to deliver opioids to patents of all ages with $E B$, as it is for non-EB patients (see Box 2).

\section{Box 2. Recommendations for acute pain care in EB}

1. Basic perioperative pain assessment and treatments should be used as for non-EB patients, with modification. (Grade: A)

2. Transmucosal (including intranasal fentanyl and trans buccal opioids) should be considered for short procedures and pain of brief duration when intravenous and enteral routes are unavailable. (Grade: B)

3. Perioperative opioid use must take preoperative exposure into consideration, with appropriate dose increases to account for tolerance. (Grade: B)

4. Regional anesthesia is appropriate for pain resulting from a number of major surgeries. Dressing of catheters must be non-adhesive and monitored carefully. (Grade: $\mathbf{C}$ )

In the postoperative period, EB patients may be slow to resume oral intake, especially after oropharyngeal procedures, such as esophageal dilatation or dental rehabilitation. For patients lacking gastrostomy tubes, intravenous analgesia may be required. Intravenous analgesia should be multimodal and may include opioids (for example, morphine or hydromorphone), nonsteroidal anti-inflammatory drugs (NSAIDS; when postoperative bleeding is not a risk and renal function is normal (for example, ketorolac)) and acetaminophen (enteral or intravenous). Given the high rate of superficial bleeding from skin wounds, cyclooxygenase- 2 inhibitors may have a role to play, given they have prothrombotic features in some studies [43]. Due to the risk of blister formation with rectal manipulation, there is controversy regarding whether the rectal route of administration may be used in EB patients [44]. Intranasal opioids can be effective for short-term treatment, if other routes are not available [45-47], and may be particularly helpful for procedures of short duration when rapid-acting analgesia is desired in the absence of intravenous access. Oral disintegrating and transbuccal formulations may be helpful as well, although they presume intact mucosa, which may not be applicable (see Box 2).

Patients with prolonged postoperative pain because of extensive surgery may benefit from the use of opioidbased PCA with dose adjustments that take into consideration prior opioid use. While no EB-specific literature exists, this modality is standard treatment in many centers for patients old enough to understand the concept (typically seven years of age or older). Activation of the dosing button may be limited by pseudosyndactyly, so use should be determined on a case-by-case basis. PCAby-proxy (dose administered by a nurse or designated family member) is practiced in some pediatric centers 
and may be an alternative approach to PCA dosing for children.

\section{Preoperative tolerance}

The preoperative pain status of the patient should be taken into consideration when choosing opioid dose, both intra- and post-operatively. Many EB patients have recurring acute and/or chronic pain and may be taking opioids daily, either prior to bathing/dressing changes or for ongoing pain. These patients require increased doses of opioids for adequate analgesic effect, due to the development of tolerance. Their usual daily opioid intake should be considered the baseline opioid dose to which the postoperative analgesia should be added (see Box 2). Drug pharmacokinetics may be altered in patients chronically exposed to sedatives and opioids. Flexibility in dosing, review of prior anesthetic records and discussion with the patient or family can aid appropriate dosing.

\section{Regional anesthesia}

Some common procedures (and the corresponding regional anesthesia technique used) in EB patients include: fundoplication (epidural) [48-50], hand and foot surgery (peripheral nerve block, either single shot or continuous peripheral nerve catheter infusion following bolus injection) and hand surgery (both axillary and infraclavicular approaches have been used for brachial plexus block) [51,52].

Regional anesthesia techniques should be modified in patients with EB to minimize damage to the skin. Skin preparation may be performed by pouring prep solution (povidone-iodine or chlorhexidine) on the site without rubbing, then blotting and allowing the solution to dry. Ultrasound guidance can be used for peripheral nerve blocks with generous use of gel to minimize skin abrasion when moving the probe. When a catheter is placed (epidural or peripheral nerve), it may be tunnelled subcutaneously if desired [53] then secured to the skin using silicone-based tapes and dressings (Mepitac ${ }^{\circledR}$, Mepitel $^{\circledR}$, Mepilex ${ }^{\circledR}$ ) or other soft non-adhesive dressings. Adhesive dressings and adhesive adjuncts should be avoided. If there is any doubt about the safety of using a dressing, it should be tested on a small area of skin with patient or parental consent. With local infection being a relative contraindication to regional anesthesia, examination of the skin overlying the point of entry is mandatory prior to attempting a catheter placement. If leaving a catheter in the epidural space is undesirable, then a single injection of a long-acting form of opioid (DepoDur ${ }^{\circledR}$ ) may be a good option when available [54,55], although monitoring is important due to risk of hypoventilation [56]. Lidocaine infiltration may be used by dentists/ oral surgeons when extractions are necessary, but care must be taken when injecting to avoid mucosal blister formation (see Box 2).

\section{Non-pharmacologic therapies}

Non-pharmacologic techniques should also be employed in combination with the pharmacologic techniques listed above. These include, but are not limited to, distraction (music, reading, video games and movies), visualization, imagery/virtual reality and breathing techniques (see Efficacy of Psychological Interventions in Chronic and Acute Pain Management, above and Box 1). Effective approaches used in the past should be discussed with the patient or parents and their use supported whenever possible.

Good practice points Postoperative pain can be managed as for other patients in the same setting, with modifications to account for the ability to self-administer medications, prior drug exposure, and the condition of the skin at potential regional anesthesia injection/catheter sites.

\section{Chronic and recurrent pain care}

EB has a large number of painful complications, some chronic and others acute but repetitive. Care of EB involves painful interventions on a daily basis. Almost every organ system can be affected, but the following are the major sources of pain: skin, gastrointestinal tract, musculoskeletal system, eyes.

\section{Skin and wound pain}

Introduction The classic presentation of EB is the development of skin wounds that are painful in their own right, but which often become infected, heal poorly and frequently lead to scarring. This combination makes skin and wound pain a prominent complaint of patients with EB.

Environmental and behavioral approaches Dressings that are non-adhesive upon removal, such as siliconebased products, are helpful in reducing skin-trauma pain. Different subtypes of EB and different individuals seem to have varying dressing requirements [57]. Nutrition is important in promoting wound healing, and anecdotally, patients with poor nutritional status have more wounds and slower healing, which lead to increased pain. Experience suggests that attention to good nutrition, surveillance for superficial infection and aggressive treatment of infection reduce pain. As discussed in the section on psychological interventions, CBT is helpful for a number of painful conditions and should be applied in EB.

Systemic approaches The pharmacological treatment of skin and wound pain is non-specific, with no evidence in the EB population to promote one treatment over another. NSAIDs, acetaminophen, tramadol and opioids 
are used with success. Cannabinoids have some anecdotal support. Itch is a major problem (see below) that can lead to increased scratching and subsequent development of painful wounds. Hence, managing pruritus is important to prevent wound-related pain.

Many patients with severe types of EB use longacting opioid preparations to provide a basal comfort level. Of note, there are no clear guidelines that longacting opioids are preferable to use of intermittent opioids for non-cancer pain [58], although there is modest evidence for opioid use, in general, for noncancer pain in adults $[58,59]$. Individualization of therapy is recommended.

Regular and frequent dosing of opioids is common and merits special attention. Regardless of the opioid chosen, chronic use of opioids may have endocrinologic effects, such as hypogonadism [60]. Monitoring should be considered, especially given the propensity for osteopenia and delayed puberty in adolescents and young adults with EB. In the absence of data, the use of opioids is recommended as clinically indicated (see Box 3).

\section{Box 3. Recommendations for wound pain treatment}

1. Maintain optimal nutrition and mobility and treat infections as indicated (Grade: D)

2. Consider topical therapies for pain (Grade: $\mathbf{C}$ )

3. Systemic pharmacologic therapy should be adapted to treat both acute and chronic forms of skin pain. (Grade: B)

4. Monitor potential long-term complications of chronically administered medications. (Grade: $\mathbf{C}$ )

Methadone merits particular consideration. Dose titration can be unpredictable due to long and variable halflife as well as to saturable plasma protein binding [61]. The long and variable half-life, as well as the risk of methadone-induced prolonged QT syndrome [62,63], mandates care in its use alone and with other drugs that may also prolong the QT interval. Guidelines on electrocardiographic screening are limited [64] (especially for adult patients of smaller stature and children). Given the risk of prolonged QT and methadone's complex and variable pharmacokinetics, it is recommended that methadone only be prescribed by practitioners with experience evaluating and monitoring its use [65]. Methadone use is, therefore, best done with input from a pain management and/or palliative care specialist.

Among the common side effects of opioids, constipation [66] and pruritus are particularly significant. Both are significant baseline problems in EB and the reader is referred to the sections on gastrointestinal pain and pruritus.

The pain of extensive wounds has a quality suggestive of neuropathic pain; both are often described as 'burning' in quality. There is evidence supporting the use of gabapentin for neuropathic pain in other conditions [67]. Medications such as tricyclic antidepressants and gabapentin have shown anecdotal success in EB skin pain in a child [68], as well as for adult patients with acute skin pain due to burns [69]. The potential for tricyclic antidepressants to prolong the QT interval means that caution should be taken using this class of medications in RDEB patients, who are at risk for developing cardiomyopathy [70], as a lethal outcome in this setting has been reported [71].

Topical approaches For localized wounds, topical lidocaine jelly ( $2 \%$ concentration) has been used anecdotally. Morphine mixed in hydrogel formulations has been used in different types of localized painful wounds [72,73] but has only limited anecdotal experience in EB wounds [74] (see Box 3). Use of these medication vehicles raises questions of absorption and systemic effects that require further investigation before full recommendations can be made. Limited anecdotal evidence supports the use of keratinocyte hydrogel dressings for poorly healing wounds and RDEB [75].

Blood draws and intravenous access as well as the need for skin biopsies are minor technical procedures that can be very distressing, especially for children. Topical anesthetics are commonly used in non-EB populations with good effect. Amethocaine appears to be more effective than a eutectic mixture of local anesthetics $\left(\mathrm{EMLA}^{\circledR}\right)$ [76]. These may have a role when applied to intact skin, but cannot be recommended for use on wounds due to unknown rate and extent of absorption of lidocaine. Blistering as a localized allergic reaction to $\mathrm{EMLA}^{\circledR}$ (or its contents) has been rarely observed, indicating caution in its use even on intact skin. Lidocaine injected with a small gauge needle is a standard approach to superficial analgesia in all age groups. Additionally, it is recommended that bicarbonate be added to buffer the $\mathrm{pH}$ of the lidocaine to reduce the pain of injection [77]. As noted above, CBT (for example, distraction and relaxation) is effective in the acute pain setting [21] and should be employed whenever possible in conjunction with medication management (see Box 1).

Good practice points Prevention and rapid healing of wounds through non-adherent dressings, optimal nutrition and infection control are priorities. 


\section{Bathing and dressing changes}

Introduction Bathing and bandage changes are a source of significant recurrent pain and anxiety for patients with EB.

Environmental treatment Oatmeal and salt have been added to bath water to reduce the pain of immersion [78]. The former may have anti-pruritic, cleansing and protective properties for dermatologic conditions in general [79] that may be similarly effective in EB. Salt is added to make the water isotonic, which has anecdotal support from many families of patients with EB including preliminary survey data from EB families [80]. Isotonic saline $(0.9 \% \mathrm{NaCl})$ is 9 grams of salt/1 liter of water; total amount of salt varying according to the desired water volume. Bleach and vinegar are anecdotally helpful in drying the skin and reducing bacterial colonization, which some patients find comforting while others report increased pain at the wound sites. The salt water does not require plain water rinse, whereas vinegar and bleach baths require rinsing to reduce the risk of itch. Many patients elect to reduce the frequency of bathing as a simple measure to minimize bath-related pain. Anecdotally, starting the bath by immersing the patient still in his/her bandages can ease the transition into the water and help reduce the pain of removing the dressings. Other patients find drafts from heating and cooling systems to be painful on open wounds, so attention to general environmental factors is recommended (see Box 4).

\section{Box 4. Recommendations for bathing and dressing} change pain treatment

1. Anxiolytics and analgesics should be used for procedural pain and fear. Care must be taken when combining such medications due to cumulative sedative effects (Grade: B).

2. Cognitive behavioral techniques should be implemented as the child becomes old enough to use them effectively. Specifically, distraction should be used for younger children (Grade: B).

3. Environmental comfort measures are recommended; these include adding salt to the water to make it isotonic and keeping the room warm (Grade: B).

Analgesics Analgesics used by patients with EB have included enteral opioids, NSAIDs and acetaminophen. The nasal route may permit administration of medications when intravenous access is absent [81]. Fentanyl works well by this route for non-EB patients in the perioperative setting [45], for breakthrough cancer pain (see section on Breakthrough pain medication at the end of life) and has been used for acute pain management in the emergency department with success [46]. Butorphanol is a mixed agonist-antagonist that can be used via the intranasal route and is effective both for pain (for example, dental postoperative pain [47]) as well as for opioidinduced pruritus. Fixed dose spray is available for outpatient use in the United States, which limits the ability to adjust for patient size. Timing of medication administration should be adjusted to match expected peak analgesia with anticipated peak pain (see Box 4).

Ketamine can be administered enterally for wound care pain, for which there are data from adult and pediatric burn populations $[82,83]$ but not for EB patients. The IV form of ketamine given orally has been used with variable success for other chronic pain conditions [84] as well as in cancer patients [85] and in pediatric palliative care [86].

Inhaled nitrous oxide has been suggested for pediatric wound care in EB in some texts and review articles [44,87], but its use in EB patients has not been studied or reported. Nitrous oxide has been used for painful procedures in other settings [88] and is available in both fixed 50:50 and variable combinations with oxygen. Depending on the delivery system (mouth piece, face mask, or nasal mask) concerns arise about environmental pollution and exposure of health care personnel [89]. In the absence of evidence of efficacy, concern must be raised about repeated use for wound care or dressing changes because of longstanding evidence of megaloblastic bone marrow changes and neurologic abnormalities due to inhibition of methionine synthase and cobalamin activity with repeated exposure to nitrous oxide [90,91].

Anxiolysis The pain caused by baths and dressing changes is commonly cited by families as generating anxiety in the patient, which in turn is stressful for the caregiver. Medications used for acute anxiolysis in this population include midazolam, diazepam and lorazepam and are considered good treatment for acute anxiety in other populations (for example, children for dental procedures, [92,93]; prior to adult burn procedures [94]). In addition to anxiolysis, the pre-procedural use of benzodiazepines offers the possibility of anterograde amnesia which may prevent the development of increased anxiety with repeated procedures. When using benzodiazepines in combination with opioids, care must be taken to avoid over sedation (see Box 4). As response to each medication will have individual variation, dose adjustments should be made carefully and preferably one drug at a time, when more than one is being administered.

Other behavioral comfort measures In addition to medication management, recommendations from caregivers 
include preparing all materials ahead of bandage removal to reduce the amount of time wounds are exposed to air. Involving children in the process at as early an age as possible helps them to develop a sense of control. Maintaining room temperature at a moderately warm level has also been recommended. CBT can be applied to treating the anxiety and pain associated with bathing and bandage changes (see section on psychological approaches, above).

Good practice points Bathing and dressing changes are recurrent sources of both pain and anxiety. Therapy should focus on both symptoms, using environmental, psychological and pharmacologic approaches.

\section{Pain related to the gastrointestinal tract}

Introduction Gastrointestinal complications are common in children and adults with EB with specific complications linked to different subtypes [95-97].

\section{Upper gastrointestinal tract}

Topical treatments Oral ulceration, blistering and mucositis are the most frequent gastrointestinal complications in patients with EB [98]. While oral ulceration can occur in all types of EB, it is most common and problematic in patients with the severe types of this disease. Oral ulceration can be extremely painful and lead to difficulties in feeding and maintaining dental hygiene. Apart from oral analgesics, topical preparations are available. Sucralfate suspension has been used to prevent and manage oral blisters in five children, 6- to 11-years-old, with RDEB when applied four times a day for six months [99]. The number of blisters reduced within three weeks and pain reduced within one week (see Box 5).

\section{Box 5. Recommendations for gastrointestinal pain} treatment

1. Topical treatments are recommended for oral and perianal pain. (Grade: C)

2. Therapy should be directed to manage gastroesophageal reflux and esophageal strictures using standard treatments. (Grade: C)

3. Constipation should be addressed nutritionally, with hydration and addition of fiber in the diet to keep stool soft, with stool softeners and by minimizing medication-induced dysmotility. (Grade: $\mathbf{C}$ )
Polyvinylpyrrolidone-sodium hyaluronate gel (Gelclair ${ }^{\circledR}$ ) either used as a mouth rinse or applied directly to a mouth lesion in children, has been used anecdotally in EB. Secondary evidence comes from two recent reviews which showed that Gelclair ${ }^{\circledR}$ may be useful as an adjunctive therapy in decreasing the painful lesions of oral mucositis in cancer patients [100,101]. Chlorhexidine gluconate and benzydamine hydrochloride mouth spray is used regularly in EB patients at the London centers with reported benefit but has not been evaluated systematically. Secondary evidence for the potential efficacy of this intervention exists for treating the pain of acute viral pharyngitis in adults [102].

Gastroesophageal reflux Patients with EB are at high risk for gastroesophageal reflux disease (GERD) - especially infants with generalized EBS, JEB and patients with severe generalized RDEB who can develop esophagitis [95]. While children with GERD may not complain of dyspeptic symptoms until they are older, crying and sleep disturbance are commonly associated with this symptom. Management is guided by standard treatment in non-EB patients, and may involve treating the reflux with antacids, histamine $\mathrm{H}_{2}$-blockers and proton pump inhibitors and, rarely, surgery [103,104] (see Box 5).

Esophageal strictures Esophageal stricture formation and dysphagia are most common in patients with severe generalized RDEB with a cumulative risk of developing strictures or stenosis rising steadily from $6.73 \%$ at age 1 year to $94.72 \%$ at age 45 years [105]. However, strictures can also be seen in other subtypes of EB including Kindler syndrome [106]. Dysphagia and delayed progression of food through the stricture can present with retrosternal chest pain. Esophageal strictures, if symptomatic, require treatment with a fluoroscopically guided balloon dilatation with peri- and post-operative steroids administered to reduce the recurrent stenosis rate [107-109] (see Box 5). Acute symptoms can respond temporarily to oral dexamethasone or nebulized budesonide, based on anecdotal evidence. A recent case report examined the use of daily oral viscous budesonide therapy $(0.5 \mathrm{mg} / 2 \mathrm{~mL}$ budesonide nebulizer solution mixed with $5 \mathrm{~g}$ of sucralose and maltodextrin) in two children with RDEB who had recurrent proximal esophageal strictures [110]. Both children had a reduction in the rate of stricture formation and symptoms of dysphagia.

\section{Lower gastrointestinal tract}

Constipation Constipation has been shown to be present in 35\% of children with all types of EB [95] and can cause abdominal pain and pain on defecation as well as lead to perianal trauma. A case of colonic perforation and early 
death resulting from severe constipation in DEB has been described [111]. Chronic perianal pain during defecation can produce stool withholding behavior which exacerbates constipation. Chronic opioid use may contribute to poor bowel motility. First line management is prevention with dietary manipulation; however, patients with severe types of $E B$ often require the regular use of a laxative (see Box 5). Polyethylene glycol is effective clinically in treating constipation in children and adults with EB, with empiric evidence of efficacy in adult [112] and pediatric [113] non-EB cohorts.

Colitis A subgroup of children with RDEB may develop colitis, presenting with abdominal pain and other symptoms $[95,114]$. Dietary restriction and anti-inflammatory drugs, such as sulfasalazine, have been used but with variable effects on controlling the colitis [95].

Perianal pain Perianal blistering and ulceration is common and debilitating in children and adults with severe types of EB. Topically, sucralfate has been shown to be superior to petroleum jelly in facilitating anal fistulotomy healing and lessening wound pain [115]. Sucralfate suspension has also been used to lessen the pain of oral and genital ulceration in patients with Behcet's disease [116]. Anecdotally, topical sucralfate combined with Cavilon ${ }^{\mathrm{TM}}$ (an alcohol-free liquid barrier film that dries quickly to form a breathable, transparent coating on the skin, containing hexamethyldisiloxane, isooctane, acrylate terpolymer, polyphenylmethylsiloxane) appears to improve pain in perianal lesions of some patients with EB. Non-surgical treatment is of small benefit for both pain and healing of chronic anal fissures [117], with recommendations of topical diltiazem and glyceryl trinitrate followed by surgery if needed in adults [118]. No data on anal fissure treatment in EB patients exist (see Box 5).

Good practice points EB affects the gastrointestinal tract in its entirety. Pain that originates from ulcerative lesions may respond to topical therapy. GERD and esophageal strictures have nutritional as well as comfort implications and should be addressed promptly when found. Maintaining good bowel habits and reducing iatrogenic causes of constipation are crucial.

\section{Musculoskeletal pain}

Introduction Musculoskeletal complications are common and frequently painful for patients with EB. These conditions include pseudosyndactyly, osteopenia, back pain, fractures and occasional co-morbid rheumatologic disorders.

Joint pain Pseudosyndactyly affects hands, feet, ankles and wrists. Painful hyperkeratotic lesions develop on the soles of patients with EBS. Occupational therapy approaches can improve function and decrease pain via use of adaptive equipment and specially designed orthotics and clothing. Physical and occupational therapy play crucial roles in encouraging patient mobility. For weight-bearing patients, careful attention to footwear, nails, orthotics and hyperkeratosis management are important aspects of pain care [119]. Referring patients to programs to maintain or regain strength, to prevent or minimize joint contractures, and to optimize mobility is recommended based on anecdotal evidence (see Box 6). Coping skills training and activity pacing can enhance effectiveness of therapy [120]. Surgical intervention has had some success in increasing mobility and reducing pain [121]. EB patients can also have inflammatory arthritis [122,123]; appropriate imaging can be helpful in determining inflammatory causes of pain. Given that inflammatory markers are usually elevated in EB patients, these markers alone are not likely to be useful to diagnose joint pathology.

\section{Box 6. Recommendations for musculoskeletal pain treatment}

1. Joint pain should be treated with mechanical interventions, physical therapy, cognitive behavioral therapy and surgical correction (Grade: C).

2. Osteoporosis should be treated to reduce pain in EB (Grade: D).

3. Back pain should be addressed with standard multi-disciplinary care (Grade: C).

Bone pain Osteopenia, osteoporosis and fractures are now well recognized and commonly seen in patients with the severest types of EB [124-126], as a cause of bone and joint pain. The causes are multifactorial and include reduced mobility, delayed puberty, limited exposure of the skin to sunlight, inadequate nutritional intake for metabolic requirements and chronic inflammation. Chronic inflammation causes increased osteoclast activity $[127,128]$.

As a consequence of the osteoporosis, a significant proportion of patients develop fractures. The incidence of vertebral fractures in patients with RDEB is unknown, but may be underestimated due to the fact that fractures of the lumbar and thoracic spine may be clinically silent, or present without overt or localized back pain on palpation [125]. Anecdotally, however, some patients can present with back pain, in which case a high index of suspicion should be maintained. Treatment of osteoporosis and derivative pain is based upon standard treatment of osteoporosis in non-EB patients, which relies on vitamin $\mathrm{D}$ and calcium supplementation, exercise and bisphosphonate treatment [129] (see Box 6). 
Anecdotally, bisphosphonates have been found useful in treating patients with evidence of osteoporosis without fracture. Bisphosphonates appear to improve fractures on annual X-rays and lead to a noticeable improvement in pain. Indirect support for the use of bisphosphonates comes from its use in rheumatologic and other pediatric conditions, associated with osteopenia $[130,131]$ and resolution of back pain $[131,132]$, but efficacy specifically in patients with EB has not been formally studied.

Back pain Older patients with EB can have back pain. Beyond osteopenia-related issues, biomechanical causes can be involved. Foot blisters and painful hyperkeratosis can cause abnormal gait and compensatory postures. Further, impaired mobility can add a myofascial component to pain. Management of back pain includes optimal foot care, assessment of primary and secondary mechanical factors, evaluation and treatment of osteopenia and fractures, physical therapy, standard analgesics and CBT interventions. Back pain treatment in the EB population is extrapolated from basic principles recommended for the general population [133], for lack of EB-specific evidence (see Box 6).

NSAIDs are routinely used for bone and joint pain of a variety of types and are appropriate for these types of pain in EB. Care should be taken to monitor for side effects, and the cyclooxygenase- 2 inhibitors may be useful in those patients who experience improved pain control but note increasing blood loss from wounds, or who have gastrointestinal upset with standard NSAIDs. Acetaminophen does not affect bleeding and can be useful. Tramadol and opioids are also useful for more severe pain. Some prefer use of long-acting opioid preparations, with methadone being the only one available in liquid form. Limitations in methadone use are discussed in sub-section on systemic approaches under Skin and Wound Pain.

Good practice points Bone health should be optimized with calcium and vitamin D supplements as needed, maintenance of maximum mobility, minimization of joint deformity and monitoring for/treatment of pubertal delay. Routine screening for bone mineral density may be useful to ascertain cases of osteopenia before they progress to osteoporosis and fractures. Care must be taken not to overlook inflammatory joint disease, as pain secondary to this will respond to disease modifying therapy. Multidisciplinary treatment modalities are helpful in addressing back pain and apply to such pain in the EB population as well.

\section{Eye pain}

Ophthalmologic involvement is pervasive in EB [134,135]. Eye pain is often caused by corneal abrasions. Comfort measures such as avoiding bright light (a natural reaction to the photophobia that results from the trauma), lubricating eye drops, NSAIDs and antibiotic drops have been used. Evidence for these treatments for recurrent corneal abrasions of other etiologies is modest [136]. The use of eye patches in non-EB patients does not aid pain relief and, therefore, is not recommended for use in EB patients either [137]. There is some evidence that topical NSAIDs provide analgesia for acute, traumatic corneal abrasions [138] (see Box 7).

\section{Box 7. Recommendations for eye pain treatment}

1. Care should include general supportive and analgesic care, protecting the eye from further damage and topical therapies (Grade: C).

Good practice points Corneal abrasions are painful and common in EB; prevention and supportive care are appropriate.

\section{Special Topics}

Pain care in infants with EB

Introduction In the severe forms of EB, pain starts immediately, and great care needs to be taken in most of the activities of daily living. Infants with EB require careful attention to environmental factors at a higher level than for older children but otherwise can receive pain care using guidelines for specific types of discomfort.

Pain assessment Pain assessment should be completed on all neonates with EB at regular intervals and as needed (see Box 8). A valid neonatal pain scale should be used, considering both physiologic and behavioral measures. Some examples include: the Premature Infant Pain Profile (PIPP) $[139,140]$, the Neonatal Pain Agitation and Sedation Scale (N-PASS) [141], the Crying, Requires oxygen, Increased vital signs, Expression and Sleepless pain scale (CRIES) [142], and the Neonatal Infant Pain Scale (NIPS) [143]. The Face Legs Arms Cry Consolability (FLACC) scale is recommended for infants between 1 to 12 months [144]. These pain scales have been validated for use by nurses, although training could be generalized to non-nurse care givers and family members. Pain should be reassessed frequently during and after interventions and until comfort is achieved based on a combination of one of the above scales and clinical judgment. Analgesic interventions should match degree or level of pain. Of note, infants, especially neonates, seem to be a higher risk 
for respiratory compromise [145,146] due to reduced clearance of opioids in infants younger than two months $[147,148]$. Therefore, careful clinical and cardiopulmonary monitoring is crucial when providing opioids to this population (see Box 8).

\section{Box 8. Recommendations for infant pain care}

1. Assess patients as needed and prior to and after interventions; health care workers should use validated measures. (Grade: A)

2. Sucrose solutions should be administered for mild to moderate pain alone or as an adjunct. (Grade: B)

3. Standard analgesics should be used in infants as in older patients with careful attention to dosing and monitoring. (Grade: B)

Procedural pain As for older patients, procedures are one of the major sources of pain for infants with EB. Wound care specifically requires a multidisciplinary team approach to ensure consistent and optimized pain control. There is evidence that a variety of pharmacologic and non-pharmacologic interventions are helpful in both term and pre-term infants [149]. Therefore, pain management interventions should precede all scheduled painful procedures, such as dressing changes, bathing and venipuncture. The range of analgesics and the routes by which they can be administered are the same as for older patients. Oral sucrose is an analgesic unique to young infants and can be used alone for mild pain (for example, immunization pain [150]) or in conjunction with other analgesics as well as physical and environmental interventions for more severe acute pain $[40,151]$.

Bathing and dressing changes To maintain appropriate moisture levels and facilitate the healing of wounds, dressings should be non-adherent as for older patients and appropriate in size. Infected wounds will require more frequent dressing changes [57,152]. Changing dressings one limb at a time is advocated in infants, to reduce the likelihood of having the skin rubbed off the opposite limb by feet kicking together, causing new, painful lesions (see Box 8). This approach also decreases the chance of bacterial spread from a colonized wound to an uncontaminated area $[57,78]$. For baths, adding salt to the water is recommended as for older patients (see subsection on environmental treatment under Bathing and Dressing Changes).

In addition to environmental adjustments, many infants will require analgesics with bath and dressing changes.
NSAIDs, acetaminophen and opioids are all used, as for older patients (see Section Bathing and Dressing Changes) (see Box 8). Codeine is not recommended, when alternatives are available, as neonates lack the capacity to metabolize the drug into active metabolites, and clinical responses are highly variable at all ages, due to polymorphisms in codeine's metabolic pathway $[153,154]$.

Severely affected hospitalized infants Severely affected newborns with deep tissue damage may require extensive pharmacologic support to achieve a level of comfort (see Box 8 ). These infants may require around the clock or continuous infusion of opioids and an adjuvant. A transition to methadone for better steady state levels should be considered (refer to sub-section on systemic approaches under Skin and Wound Pain) for caveats about methadone use). A case study has shown effective pain control in an infant with severe chronic pain (and possibly pruritus) when treated with gabapentin [155]. Patients receiving frequent opioid treatment may require extra care in avoiding opioid-induced constipation and in maintaining adequate caloric intake.

Oral ketamine has been used to supplement opioids when pain associated with dressing changes is severe [156]. Use of ketamine raises concerns due to findings of adverse neurodevelopmental effects in young animals who received prolonged intravenous infusions of ketamine [157]. However, these effects are not known to occur in human infants and are unlikely to occur with small doses administered at intervals.

Good practice points Infants benefit from the same range of analgesics as older patients. They can uniquely benefit from oral sucrose for brief painful episodes. Careful monitoring is crucial in infants receiving sedating medications. Babies with EB and their parents benefit from close physical contact like any other families. Holding and cuddling can be done safely, with scrupulous attention to lifting and handling in order to prevent new lesions and pain.

\section{End of life pain care}

Introduction The epidemiology of death in EB varies by type [158], but is not limited to dermatologic causes. Patients with JEB, generalized severe type are at greatest risk of fatality early in life from a range of causes $[159,160]$. Persons with RDEB may succumb in early to mid-adulthood from multiple causes [161-163] whereas patients with generalized types of EB simplex are at risk of laryngotracheal complications [164].

The palliative approach to pain experienced by individuals who are facing life-threatening illness addresses the physical, emotional and spiritual suffering of the patient 
and includes support for the whole family [165-167] (see Box 9). Squamous cell carcinoma is frequently diagnosed in patients with severe subtypes [168] and can present challenges typical of cancer-related pain when it metastasizes. The World Health Organization ladder approach to pain care for those patients with cancer and other persistent illnesses recommends a two-step 'ladder' as a framework for pain care [169].

\section{Box 9. Recommendations for end of life pain treatment}

1. Assess and manage physical, emotional and spiritual suffering of the patient, while providing support for the whole family. (Grade: A)

2. Opioids are the cornerstone of good analgesia in this setting. Opioid rotation may need to be considered to improve analgesia and reduce side effects, and adjuncts may need to be added. (Grade: B)

3. Consider targeted medication for neuropathic pain or when pain proves refractory to convention therapies. (Grade: D)

4. Continuous subcutaneous infusion of medication is an option when parenteral therapy is needed in the terminal phase.

(Grade: C)

5. Where needed, breakthrough medication can be given transmucosally (oral or nasal) for rapid onset and avoidance of the enteral route. (Grade: B)

Opioids Opioids have a role in EB pain management, as previously indicated in these guidelines (see Box 9). Patients in the palliative phase of their illness may be given an oral opioid sustained release medication [170]. Opioids should be titrated against pain and side effects, with differences in approach needed depending on issues such as opioid tolerance and rate of development of new pain problems [170]. However, if appropriate opioid increases are not effective, it is important to consider pharmacologic tolerance, poor absorption and neuropathic pain. Tolerance can be addressed by rotating the opioid to capitalize upon incomplete cross-tolerance [171,172]. In the face of poor absorption, parenteral therapy may be needed (see below). If neuropathic pain is suspected, methadone may be an option to consider. It has N-methyl-D-aspartate (NMDA) antagonist action in addition to mu-agonist properties common to standard opioids, and can be beneficial for neuropathic pain [173] and does not rely on renal excretion [61], which may be reduced in the palliative phase of EB [87].
Although a recent meta-analysis could not establish differences in efficacy among types of opioids for neuropathic pain, it was determined that intermediate term (weeks to months) use of opioids for neuropathic pain may be helpful [174]. Cautions in the use of methadone are discussed in the sub-section on systemic approaches under Skin and Wound Pain.

Adjunctive measures for neuropathic pain Many EB patients will have been treated with adjunctive agents such as amitriptyline or gabapentin earlier in their illness, often with good effect $[87,155]$. These both may take a period of time to achieve full analgesic effect and usually need to be given by the enteral route. Ketamine is more rapidly effective and can be given orally [84-86,175] or used subcutaneously (see below). It should be noted that when ketamine by-passes hepatic first pass metabolism, the relative proportion of norketamine is reduced and the patient may experience more sedation and hallucinations and less analgesia for a given dose [175]. Other options for addressing neuropathic pain (see Box 9) in terminal care include opioid rotation to methadone (see above), which can also be included in a subcutaneous infusion (see below).

Infusions and issues of drug delivery Parenteral administration of analgesia may be needed in the palliative phase, when ability to take enteral medications is no longer an option or if rapid escalation of therapy is needed. There has been an historic reluctance to use continuous subcutaneous infusions, due to the fear of precipitating further blistering. However, subcutaneous infusions have been reported to be tolerated in the final days of life in an adult EB patient [176] (see Box 9).

In non-EB patients with cancer pain, the subcutaneous route of morphine is effective to a similar degree as the intravenous [177]. Other alternatives, such as adherent transdermal delivery systems, need regular removal and replacement. Repeated subcutaneous/intramuscular injections are very frightening for children, as are attempts to obtain IV access. Alternatively, sites of subcutaneous needle insertion last reasonably well $[87,177]$. If subcutaneous sites do become inflamed, some benefit has been shown from adding low dose dexamethasone to the infusion [178], although this has not been used to our knowledge in children with EB.

Breakthrough pain medication at the end of life Even when good baseline pain relief has been achieved, most patients will require occasional 'breakthrough' doses of analgesia. Uniformly effective breakthrough dosing protocols have not been determined for children with EB at end of life, although there are general recommendations 
from several international sources $[169,179]$ and data to support the use of up to $20 \%$ of total daily opioid consumption $[180,181]$ in adults with cancer. In general, a short-acting, immediate release form of opioid should be given at approximately $10 \%$ to $15 \%$ of the total background opioid dose of the previous 24 hours. If rescue dosing is used frequently and consistently, then the baseline opioid dosing needs to be increased. Individual patient factors should be taken into consideration (including prior opioid exposure, renal and hepatic function, other medication use) and consultation with an expert in pain management and/or palliative care is recommended. The same principle is recommended for opioids given via all routes of administration. When very rapid onset is needed, transmucosal administration of opioids may be preferable (see Box 9). Commercially available transmucosal preparations of fentanyl are available in doses likely to be suitable for older children and adults. Evidence supports the use of transbuccal fentanyl for breakthrough pain in cancer patients [182]. An additional benefit of fentanyl is that it is not dependent on renal excretion. In some centers, the injectable formulations of morphine or diamorphine have been used buccally at around a third of the standard enteral dose (equivalent to the intravenous dose), allowing more flexibility of dosing. It is also important to remember that extreme anxiety may confound pain perception or expression and that there may be benefit in offering additional doses of buccal midazolam where this is felt to be a significant factor. Therapy should be targeted at specific symptoms whenever possible, although combination therapy is not unusual. Breakthrough analgesia should be offered in the face of unexplained 'agitation' in case of undiagnosed pain, after which medication for primary agitation/anxiety may be considered. While it is likely that both of these would cause a degree of sedation at higher doses, this should not be the primary aim of treatment.

Good practice points Palliative pain care is an expected part of care for EB, which in many cases is life-limiting in nature. All basic principles of palliative care apply as they do for other terminal disease states.

\section{Pruritus}

Introduction Itch is a prominent, debilitating and damaging symptom for children with EB, but the mechanisms which lead to the manifestation of pruritus are poorly understood [183]. Promising new insights into the causes and potential treatments of chronic itch in animal models [184], in human chronic itch generally [185] and in recovering burn patients [186] may hold potential for application in the EB population.
Non-pharmacological approaches Multiple environmental and behavioral approaches to address itch have been suggested [183,187] and include: prevention of dry skin (systemic hydration and emollients), gentle debridement of dry/dead/crusted skin, prevention and treatment of skin wound infection; maintaining/supporting the healing process by attention to anemia and nutritional status, limiting damage to the skin by avoiding shear forces imposed by scratching (short nails, occlusive barriers, patting rather than pulling or tearing at a site), avoiding overheating and using measures to keep the body cool (see Box 10). CBT is useful to reduce habitual scratching behaviors (see section on psychological approaches). It is important to avoid and treat secondary causes when present (such as drugs, environmental itch triggers, underlying co-morbidities). Opioid-induced itch in EB can be a problem and a difficult side effect to balance against the desired analgesia; opioid rotation may be helpful.

\section{Box 10. Recommendations for itch treatment \\ 1. Use environmental and behavioral interventions for itch control. (Grade: C) \\ 2. Antihistamines are recommended and can be chosen depending upon desirability of sedating effects. (Grade: D) \\ 3. Gabapentin, pregabalin, TCA, serotonin norepinephrine reuptake inhibitors (SNRIs) and other non-traditional antipruritic agents should be strongly considered for itch treatment. (Grade: C)}

Pharmacological therapies Pharmacological therapies include traditional oral antihistaminic medications (see Box 10). Some patients prefer sedating formulations at bedtime (for example, diphenhydramine, hydroxyzine, chlorpheniramine) and others non-sedating preparations during the day (for example, cetirizine, loratadine and fexofenadine). Efficacy is variable and recommendations are based on anecdotal experience for lack of good evidence in EB and other dermatologic conditions. Centrally acting medications, such as gabapentin and pregabalin, have evidence for efficacy from the burn literature $[186,188,189]$ and may have application in EB. Many of these medications have also been used successfully for neuropathic pain (see sub-section on adjunctive measures for neuropathic pain under End of Life Pain). Antidepressants with nortriptyline re-uptake inhibitory actions have been used for various pruritic conditions with some evidence for efficacy, with mirtazapine showing 
promise [190-193]. Low-dose cyclosporine has been used in a single case of dominant dystrophic EB to reduce generalized itching $[185,194]$. Anecdotal success has been reported with ondansetron in EB; however, the same had been reported for pruritus from cholestatic jaundice, although controlled trials did not confirm efficacy [195]. Similar suggestions were made related to the pruritus of uremia [196,197], leading to recommendations that ondansetron should be considered, although clinical trials are needed in EB.

Other medications that have shown sporadic clinical success in treating itch in EB include: cyproheptadine; selective serotonin re-uptake inhibitors (SSRIs; fluoxetine, paroxetine, sertraline, fluvoxamine) [193]; tricyclic antidepressants (doxepin, amitriptyline, nortriptyline) [192]; opioid antagonists (naloxone, naltrexone); kappa receptor agonists (butorphanol, dextromethorphan, nalbuphine); other 5-HT3 receptor antagonists (granisetron, dolasetron); antipsychotic agents (olanzapine, pimozide) and cannabinoids. These agents and the NK-1 receptor antagonist aprepitant may prove to be useful in certain subsets of patients, although evidence to guide therapy is lacking [198] and practitioners are encouraged to pursue the aforementioned therapies based on patient response to prior medications, potential interactions within the patient's medication list and medication availability (see Box 10).

It is common practice for medications from different drug classes to be used concurrently and for agents in the same class to be rotated due to the observation that a particular medication may have improved efficacy after intermittent drug holiday.

Good practice points A combination of environmental, cognitive-behavioral and pharmacologic therapies is available for use for EB-related pruritus, which can be a severe symptom of the disease.

\section{Conclusions}

These guidelines represent the initial effort to organize pain management for patients with EB based on existing evidence. While the guidelines were developed using current evidence and a rigorous evaluation process, there are limitations in the clinical use of the recommendations. The two

\section{Table 5 Implementation barriers}

1. Availability of resources (for example, medications and equipment)

2. Legal and social restrictions on the use of various medications and therapies.

3. Limited and uneven distribution of knowledge and expertise

4. International dissemination of guidelines and EB-related information to local care providers and families (includes translation and access to electronic and print media)
Table 6 Areas of research

Psychological and integrative approaches:

1. Test the efficacy of well-established cognitive behavioral interventions for acute and chronic pain management in EB.

2. Develop EB-specific pain assessment measures for both acute and chronic pain.

3. Evaluate the efficacy of cognitive behavioral therapy for EB-related pruritus

4. Evaluate the role for Integrative Medicine techniques for the EB population.

\section{Acute pain:}

1. Improve the balance between analgesia and side effects specific to EB (for example, itching).

2. Establish optimal treatment of needle-related pain.

3. Define the role for ketamine and other non-opioid agents.

\section{Chronic and recurrent pain:}

1. Evaluate topical therapies including opioids, local anesthetics and NSAIDs.

2. Determine optimal environmental interventions for bath and dressing changes including bath additives (salt, bleach, oatmeal).

3. Define optimal perianal pain therapies.

4. Clarify the role of bone density screening in preventing bone pain and fractures.

5. Determine the role of topical NSAIDs in treatment of corneal abrasion pain.

6. Explore the role for various physical and occupational therapy interventions for joint, bone and back pain.

Infants:

1. Validate observational pain scales in the setting of bandaged infants.

2. Determine the safety and dosing of adjunct medications, such as gabapentin and topical agents.

\section{Pruritus:}

1. Establish the mechanisms of pruritus in EB and effective treatment thereof.

2. Refine the management of opioid-exacerbated itch.

\section{End of life:}

1. Define how best to integrate palliative care into the overall care of patients with EB prior to end of life.

2. Define optimal treatments for pain at the end of life.

A focused list to represent the broad categories that would benefit from studies in patients with EB.

broad areas of concern involve practical limitations of implementation and the level of available evidence. Tables 5 and 6 identify issues for implementation of the guidelines as well as general recommendations areas for research to enhance the level of evidence.

\section{Additional file}

Additional file 1: EB-specific articles that were excluded from use in making recommendations, with rationales. 


\section{Abbreviations}

CBT: cognitive behavioral therapy/techniques; CHEOPS: Children's Hospital of Eastern Ontario Pain Scale; CRIES: Crying, requires oxygen, Increased vital signs, Expression and Sleepless Pain Scale; DDEB: dominant dystrophic epidermolysis bullosa; DEB: dystrophic epidermolysis bullosa (dominant and recessive types); EB: epidermolysis bullosa; EBS: epidermolysis bullosa simplex (basal and suprabasal types); FLACC: Face Legs Arms Cry Consolability Pain Scale; GERD: gastroesophageal reflux disease; JEB: junctional epidermolysis bullosa (generalized and localized); NIPS: Neonatal Infant Pain Scale; NMDA: N-methyl-d-aspartate; NSAIDs: non-steroidal anti-inflammatory drugs; N-PASS: Neonatal Pain Agitation and Sedation Scale; PCA: patient controlled analgesia; PIPP: Premature Infant Pain Profile; RDEB: recessive dystrophic epidermolysis bullosa.

\section{Competing interests}

The authors declare that they have no competing interests.

\section{Authors' contributions}

This work was initiated and led by KRG with active input from all authors. JG, $E H, C L, A L J, A E M, L G M$ and DSL participated in the review process and recommendation/guideline draft, see text for details. DSL led the systematic evidence analysis and provided methodological support and guidance. Multi-disciplinary clinician input was obtained as was input from patients and families early in the process (see Acknowledgments, below). The consensus meeting (see text) was attended in person or via Skype by KRG, ALJ, EH, JG, CL, LGM and BK (see Acknowledgements). All authors read and approved the final manuscript.

\section{Acknowledgments}

Guideline development was supported by a small grant from DEBRA USA to defray the costs of travel, accommodation and preparation related to the consensus meeting, held on 4, 5 May 2012 in Cincinnati, Ohio, USA. The following members of the original guidelines development committee helped with initial content development and recommendations: Beverly Inge Walti, Kara Malcolm, Teresa Mingrone, and Stacy Shipley.

The following Clinician Reviewers are gratefully acknowledged: Anna L. Bruckner, MD, Elizabeth Ely, RN, PhD, Kim Hazelbaker, RN, Barbara Hoggart, MD, Richard F. Howard, BSc, FRCA, Anne Lucky, MD, Geraldine Mancuso-Kelly, RN, Elena Pope, MD, Susan Rowe, RN, Alexandra Szabova, MD, Jean Whalen, RN. Warm thanks to the following Family and Patient Reviewers: Patsy DiGiovanna, Michelle Starkey, Natasha Starkey and *Brett Kopelan (*participated in consensus meeting).

Special thanks to Andrea Ayers (administrative assistant to KRG), Brett Kopelin (DEBRA USA), Francis Palisson (DEBRA Chile) and Avril Keenan (DEBRA Ireland) for their support.

\section{Author details}

${ }^{1}$ Pain Management Center, Department of Anesthesiology, Cincinnati Children's Hospital Medical Center, Cincinnati, Ohio, USA. ${ }^{2}$ Lucille Packard Children's Hospital, Department of Anesthesia (by courtesy, Pediatrics), Stanford University, Stanford, California, USA. ${ }^{3}$ Helen and Douglas Hospices, Oxford and John Radcliffe Hospital, Oxford, USA. ${ }^{4}$ University of Southampton, Southampton, UK. ${ }^{5}$ Great Ormond Street Hospital for Children NHS Trust, London, UK. ${ }^{6}$ Pain Management Center and Division of Behavioral Medicine and Clinical Psychology, Cincinnati Children's Hospital Medical Center, Cincinnati, Ohio, USA ${ }^{7}$ National Paediatric Epidermolysis Bullosa Centre, Great Ormond Street Hospital NHS Foundation Trust, London, UK. ${ }^{8}$ Department of Anesthesiology and Critical Care, Children's Hospital of Philadelphia, Philadelphia, Pennsylvania, USA. ${ }^{9}$ James M. Anderson Center for Health Systems Excellence, Cincinnati Children's Hospital Medical Center, Cincinnati, Ohio, USA.

Received: 19 December 2013 Accepted: 9 September 2014 Published online: 09 October 2014

\section{References}

1. Fine JD, Johnson LB, Weiner M, Suchindran C: Assessment of mobility, activities, and pain in different subtypes of epidermolysis bullosa. Clin Exp Dermatol 2004, 29:122-127.

2. Tabolli S, Sampogna F, Di Pietro C, Paradisi A, Uras C, Zotti P, Castiglia D, Zambruno G, Abeni D: Quality of life in patients with epidermolysis bullosa. Br J Dermatol 2009, 161:869-877.
3. Margari F, Lecce PA, Santamato W, Ventura P, Sportelli N, Annicchiarico G, Bonifazi E: Psychiatric symptoms and quality of life in patients affected by epidermolysis bullosa. J Clin Psychol Med Settings 2010, 17:333-339.

4. Van Scheppingen C, Lettinga AT, Duipmans JC, Maathius CG, Jonkman MF: Main problems experienced by children with Epidermolysis Bullosa: a qualitative study with semi-structured interviews. Acta Derm Venerol 2008, 88:143-150.

5. Fine J, Bruckner-Tuderman L, Eady RA, Bauer EA, Bauer JW, Has C, Heagerty A Hintner H, Hovnanian A, Jonkman MF, Leigh I, Marinkovich P, Martinez AE, McGrath JA, Mellerio JE, Moss C, Murrell DF, Shimizu H, Uitto J, Woodley D, Zambruno G: Inherited epidermolysis bullosa: updated recommendations on diagnosis and classification. J Am Acad Dermatol 2014, 70:1103-1126.

6. Debra International [http://www.debra-international.org/homepage.html]

7. Clark E, Burkett K, Stanko-Lopp D: Let Evidence Guide Every New Decision (LEGEND): an evidence evaluation system for point-of-care clinicians and guideline development teams. J Eval Clin Pract 2009, 15:1054-1060.

8. Cincinnati Children's Hospital Medical Center: LEGEND documents. 2013. http://www.cincinnatichildrens.org/service/j/anderson-center/evidencebased-care/legend/.

9. Brozek JL, Akl EA, Alonso-Coello P, Lang D, Jaeschke R, Williams JW: Grading quality of evidence and strength of recommendations in clinical practice guidelines. Part 1 of 3 . An overview of the GRADE approach and grading quality of evidence about interventions. Allergy 2009, 64:669-677.

10. Guyatt GH, Oxman AD, Vist GE, Kunz R, Falck-Ytter Y, Alonso-Coello P, Schünemann HJ, GRADE Working Group: GRADE: an emerging consensus on rating quality of evidence and strength of recommendations. BMJ 2008, 336:924-926.

11. Debra International pain management guidelines page [http://www. debra-international.org/med-professionals/best-clinical-practice-guidelinesbcpg/pain-management.html]

12. Gatchel RJ, Peng YB, Peters ML, Fuchs PN, Turk DC: The biopsychosocial approach to chronic pain: scientific advances and future directions. Psychol Bull 2007, 133:581-624.

13. Gerik SM: Pain management in children: developmental considerations and mind-body therapies. South Med J 2005, 98:295-302.

14. Green JP, Barabasz AF, Barrett D, Montgomery GH: Forging ahead: the 2003 APA Division 30 definition of hypnosis. Int J Clin Exp Hypn 2005, 53:259-264.

15. Palermo TM, Chambers CT: Parent and family factors in pediatric chronic pain and disability: an integrative approach. Pain 2005, 119:1-4.

16. Eccleston C, Palermo TM, Williams AC, Lewandowski A, Morely S: Psychological therapies for the management of chronic and recurrent pain in children and adolescents. Cochrane Database Syst Rev 2009, 2, CD003968.

17. Palermo TM, Eccleston C, Lewandowski AS, Williams AC, Morley S: Randomized controlled trials of psychological therapies for management of chronic pain in children and adolescents: an updated meta-analytic review. Pain 2010, 148:387-397.

18. Kashikar-Zuck S, Swain NF, Jones BA, Graham TB: Efficacy of cognitivebehavioral intervention for juvenile primary fibromyalgia syndrome. J Rheumatol 2005, 32:1594-1602.

19. Eccleston C, Williams AC, Morley S: Psychological therapies for the management of chronic pain (excluding headache) in adults. Cochrane Database Syst Rev 2009, 2, CD007407.

20. Richardson J, Smith JE, McCall G, Pilkington K: Hypnosis for procedure-related pain and distress in pediatric cancer patients: a systematic review of effectiveness and methodology related to hypnosis interventions. J Pain Symptom Manage 2006, 31:70-84.

21. Uman LS, Chambers CT, McGrath PJ, Kisely S: Psychological interventions for needle-related procedural pain and distress in children and adolescents. Cochrane Database Syst Rev 2006, 4, CD005179.

22. Chambers CT, Taddio A, Uman LS, McMurtry CM, HELPinKIDS Team: Psychological interventions for reducing pain and distress during routine childhood immunizations: a systematic review. Clin Ther 2009, 31:S77-S103.

23. Kleiber C, Harper DC: Effects of distraction on children's pain and distress during medical procedures: a meta-analysis. Nurs Res 1999, 48:44-49.

24. Liossi $C$, White $P$, Hatira $P$ : A randomized clinical trial of a brief hypnosis intervention to control venepuncture-related pain of paediatric cancer patients. Pain 2009, 142:255-263.

25. Malloy KM, Milling LS: The effectiveness of virtual reality distraction for pain reduction: a systematic review. Clin Psychol Rev 2010, 30:1011-1018. 
26. Hanson MD, Gauld M, Wathen CN, Macmillan HL: Nonpharmacological interventions for acute wound care distress in pediatric patients with burn injury: a systematic review. J Burn Care Res 2008, 29:730-741.

27. Liossi C, Franck L: Psychological interventions for acute pediatric pain. In Clinical Pain Management Acute Pain. Edited by Macintyre P, Rowbotham D, Walker S. London: Hodder Arnold: 2008:308-323.

28. Hagermark O, Wahlgren C: Treatment of itch. Semin Dermatol 1995, 14:320-325.

29. Chida Y, Steptoe A, Hirakawa N, Sudo N, Kubo C: The effects of psychological intervention on atopic dermatitis. A systematic review and meta-analysis. Int Arch Allergy Immunol 2007, 144:1-9.

30. Azrin NH, Nunn RG: Habit-reversal: a method of eliminating nervous habits and tics. Behav Res Ther 1973, 11:619-628.

31. Rosenbaum MS, Ayllon T: The behavioral treatment of neurodermatitis through habit-reversal. Behav Res Ther 1981, 19:313-318.

32. Ehlers A, Stangier U, Gieler U: Treatment of atopic dermatitis: a comparison of psychological and dermatological approaches to relapse prevention. J Consult Clin Psychol 1995, 63:624-635.

33. Hopton A, MacPherson H: Acupuncture for chronic pain: is acupuncture more than an effective placebo? A systematic review of pooled data from meta-analyses. Pain Pract 2010, 10:94-102.

34. Cepeda MS, Carr DB, Lau J, Alvarez H: Music for pain relief. Cochrane Database Syst Rev 2006, 2, CD004843.

35. Bussing A, Ostermann T, Ludtke R, Michalsen A: Effects of yoga interventions on pain and pain-associated disability: a meta-analysis. J Pain 2012, 13:1-9.

36. Cordier W, Steenkamp V: Herbal remedies affecting coagulation: a review. Pharm Biol 2012, 50:443-452.

37. Kashikar-Zuck S, Lynch AM: Psychological interventions for chronic pain. In Pain in Children: A Practical Guide for Primary Care. Edited by Walco GA, Goldschneider KR. Totowa, NJ: Humana Press; 2008:145-152.

38. Power N, Liossi C, Franck L: Helping parents to help their child with procedural and everyday pain: practical, evidence-based advice. I Spec Pediatr Nurs 2007, 12:203-209.

39. von Baeyer CL, Spagrud LJ: Systematic review of observational (behavioral) measures of pain for children and adolescents aged 3 to 18 years. Pain 2007, 127:140-150.

40. Stinson JN, Kavanagh T, Yamada J, Gill N, Stevens B: Systematic review of the psychometric properties, interpretability and feasibility of self-report pain intensity measures for use in clinical trials in children and adolescents. Pain 2006, 125:143-157.

41. Goldschneider K, Lucky AW, Mellerio JE, Palisson F, del Carmen Viñuela Miranda M, Azizkhan RG: Perioperative care of patients with epidermolysis bullosa: proceedings of the 5 th international symposium on epidermolysis bullosa, Santiago Chile, December 4-6, 2008. Pediatr Anaesth 2010, 20:797-804.

42. Goldschneider KR, Lucky AW: Pain management in epidermolysis bullosa. Dermatol Clin 2010, 28:273-282.

43. Steffel J, Luscher TF, Ruschitzka F, Tanner FC: Cyclooxygenase-2 inhibition and coagulation. J Cardiovasc Pharmacol 2006, 47:S15-S20.

44. Herod J, Denyer J, Goldman A, Howard R: Epidermolysis bullosa in children: pathophysiology, anaesthesia and pain management. Paediatr Anaesth 2002, 12:388-397.

45. Manjushree R, Lahiri A, Ghosh BR, Laha A, Handa K: Intranasal fentanyl provides adequate postoperative analgesia in pediatric patients. Can J Anaesth 2002, 49:190-193.

46. Borland M, Jacobs I, King B, O'Brien D: A randomized controlled trial comparing intranasal fentanyl to intravenous morphine for managing acute pain in children in the emergency department. Ann Emerg Med 2007, 49:335-340.

47. Desjardins PJ, Norris LH, Cooper SA, Reynolds DC: Analgesic efficacy of intranasal butorphanol (Stadol NS) in the treatment of pain after dental impaction surgery. J Oral Maxillofac Surg 2000, 58:19-26.

48. Kelly RE: Regional anesthesia in children with epidermolysis bullosa dystrophica. Anesthesiology 1988, 68:469.

49. Sopchak AM, Thomas PS, Clark WR: Regional anesthesia in a patient with epidermolysis bullosa. Reg Anesth 1993, 18:132-134.

50. Yee LL, Gunter JB, Manley CB: Caudal epidural anesthesia in an infant with epidermolysis bullosa. Anesthesiology 1989, 70:149-151.

51. Diwan R, Vas L, Shah T, Raghavendran S, Ponde V: Continuous axillary block for upper limb surgery in a patient with epidermolysis bullosa simplex. Paediatr Anaesth 2001, 11:603-606.
52. Englbrecht JS, Langer M, Hahnenkamp K, Ellger B: Ultrasound-guided axillary plexus block in a child with dystrophic epidermolysis bullosa. Anaesth Intensive Care 2010, 38:1101-1105.

53. Doi S, Horimoto Y: Subcutaneous tunnelling of an epidural catheter in a child with epidermolysis bullosa. Acta Anaesth Scand 2006, 50:394-395.

54. Viscusi ER, Martin G, Hartrick CT, Singla N, Manvelian G, EREM Study Group: Forty-eight hours of postoperative pain relief after total hip arthroplasty with a novel, extended-release epidural morphine formulation. Anesthesiology 2005, 102:1014-1022.

55. Mhuircheartaigh RJ, Moore RA, McQuay HJ: Analysis of individual patient data from clinical trials: epidural morphine for postoperative pain. $\mathrm{Br} J$ Anaesth 2009, 103:874-881.

56. Hartrick CT, Hartrick KA: Extended-release epidural morphine (DepoDur): review and safety analysis. Expert Rev Neurother 2008, 8:1641-1648.

57. Denyer JE: Wound management for children with epidermolysis bullosa. Dermatol Clin 2010, 28:257-264.

58. Chou R, Fanciullo GJ, Fine PG, Adler JA, Ballantyne JC, Davies P, Donovan MI, Fishbain DA, Foley KM, Fudin J, Gilson AM, Kelter A, Mauskop A, O'Connor PG, Passik SD, Pasternak GW, Portenoy RK, Rich BA, Roberts RG, Todd KH, Miaskowski C, American Pain Society-American Academy of Pain Medicine Opioids Guidelines Panel: Clinical guidelines for the use of chronic opioid therapy in chronic noncancer pain. J Pain 2009, 10:113-130.

59. Noble M, Treadwell JR, Tregear SJ, Coates VH, Wiffen PJ, Akafomo C, Schoelles KM: Long-term opioid management for chronic noncancer pain. Cochrane Database Syst Rev 2010, 1, CD006605.

60. Katz N, Mazer NA: The impact of opioids on the endocrine system. Clin J Pain 2009, 25:170-175.

61. Davies $D$, Vlaming $D$, Haines $C$ : Methadone analgesia for children with advanced cancer. Pediatr Blood Cancer 2008, 51:393-397.

62. Huh B, Park CH: Retrospective analysis of low-dose methadone and QTC prolongation in chronic pain patients. Korean J Anesthesio/ 2010, 58:338-343.

63. Cruciani RA: Methadone: to ECG or not to ECG... That is still the question. J Pain Symptom Manage 2008, 36:545-552.

64. Martin JA, Campbell A, Killip T, Kotz M, Krantz MJ, Kreek MJ, McCarroll BA, Mehta D, Payte JT, Stimmel B, Taylor T, Haigney MC, Wilford BB, Substance Abuse and Mental Health Services Administration: QT interval screening in methadone maintenance treatment: report of a SAMHSA expert panel. J Addict Dis 2011, 30:283-306.

65. Nicholson AB: Methadone for cancer pain. Cochrane Database Syst Rev 2009, 4, CD003971.

66. Camilleri M: Opioid-induced constipation: challenges and therapeutic opportunities. Am J Gastroenterol 2011, 106:835-842.

67. Moore RA, Wiffen PJ, Derry S, McQuay HJ: Gabapentin for chronic neuropathic pain and fibromyalgia in adults. Cochrane Database Syst Rev 2011, 3, CD007938

68. Chiu YK, Prendiville JS, Bennett SM, Montgomery CJ, Oberlander TF: Pain management of junctional epidermolysis bullosa in an 11-year-old boy. Pediatr Dermatol 1999, 16:465-468.

69. Gray P, Williams B, Cramond T: Successful use of gabapentin in acute pain management following burn injury: a case series. Pain Med 2008, 9:371-376.

70. Lara-Corrales I, Mellerio JE, Martinez AE, Green A, Lucky AW, Azizkhan RG, Murrell DF, Agero AL, Kantor PF, Pope E: Dilated cardiomyopathy in epidermolysis bullosa: a retrospective, multicenter study. Pediatr Dermatol 2010, 27:238-243.

71. Taibjee SM, Ramani P, Brown R, Moss C: Lethal cardiomyopathy in epidermolysis bullosa associated with amitriptyline. Arch Dis Child 2005, 90:871-872

72. Twillman RK, Long TD, Cathers TA, Mueller DW: Treatment of painful skin ulcers with topical opioids. J Pain Symptom Manage 1999, 17:288-292.

73. LeBon B, Zeppetella G, Higginson IJ: Effectiveness of topical administration of opioids in palliative care: a systematic review. J Pain Symptom Manage 2009, 37:913-917.

74. Watterson G, Howard R, Goldman A: Peripheral opioids in inflammatory pain. Arch Dis Child 2004, 89:679-681.

75. Than MP, Smith RA, Cassidy S, Kelly R, Marsh C, Maderal A, Kirsner RS: Use of a keratin-based hydrogel in the management of recessive dystrophic epidermolysis bullosa. J Dermatol Treat 2013, 24:290-291.

76. Lander JA, Weltman BJ, So SS: EMLA and amethocaine for reduction of children's pain associated with needle insertion. Cochrane Database Syst Rev 2006, 3, CD004236 
77. Cepeda MS, Tzortzopoulou A, Thackrey M, Hudcova J, Arora Gandhi P, Schumann R: Adjusting the $\mathrm{pH}$ of lidocaine for reducing pain on injection. Cochrane Database Syst Rev 2010, 12, CD006581.

78. Arbuckle HA: Bathing for individuals with Epidermolysis bullosa. Dermatol Clin 2010, 28:265-266.

79. Cerio R, Dohil M, Jeanine D, Magina S, Mahé E, Stratigos AJ: Mechanism of action and clinical benefits of colloidal oatmeal for dermatologic practice. J Drugs Dermatol 2010, 9:1116-1120.

80. Peterson B, Berman S, Arbuckle A: The effectiveness of saltwater baths in the treatment of patients with epidermolysis bullosa. Poster presented at the 37th Annual Meeting of the Society of Pediatric Dermatology, Baltimore July 7-10, 2011.

81. Wolfe TR, Braude DA: Intranasal medication delivery for children: a brief review and update. Pediatrics 2010, 126:532-537.

82. Ezike HA, Odiakosa MC: Oral ketamine for wound care procedures in adult patients with burns. South Afr J Anaesth Analg 2011, 17:242-248.

83. Humphries Y, Melson M, Gore D: Superiority of oral ketamine as an analgesic and sedative for wound care procedures in the pediatric patient with burns. J Burn Care Rehabil 1997, 18:34-36.

84. Blonk MI, Koder BG, van den Bemt PM, Huygen FJ: Use of oral ketamine in chronic pain management: a review. Eur J Pain 2010, 14:466-472.

85. Bell RF, Eccleston C, Kalso EA: Ketamine as an adjuvant to opioids for cancer pain. Cochrane Database Syst Rev 2012, 11, CD003351.

86. Ugur F, Gulcu N, Boyaci A: Oral ketamine for pain relief in a child with abdominal malignancy. Pain Med 2009, 10:120-121.

87. Watterson G, Denyer J, Hain R: Skin Symptoms. In Oxford Textbook of Palliative Care for Children. Edited by Goldman A, Hain R, Liben S. Oxford, UK: Oxford University Press; 2005:448-459.

88. Burton JH, Auble TE, Fuchs SM: Effectiveness of 50\% nitrous oxide/50\% oxygen during laceration repair in children. Acad Emerg Med 1998, 5:112-117.

89. Rowland AS, Baird DD, Shore DL, Weinberg CR, Savitz DA, Wilcox AJ: Nitrous oxide and spontaneous abortion in female dental assistants. Am J Epidemiol 1995, 141:531-538.

90. Nunn JF, Chanarin I, Tanner AG, Owen ER: Megaloblastic bone marrow changes after repeated nitrous oxide anaesthesia. Reversal with folinic acid. Br J Anaesth 1986, 58:1469-1470.

91. Sanders RD, Weimann J, Maze M: Biologic effects of nitrous oxide: a mechanistic and toxicologic review. Anesthesiology 2008, 109:707-722.

92. Lourenço-Matharu L, Ashley PF, Furness S: Sedation of children undergoing dental treatment. Cochrane Database Syst Rev 2012, 3, CD003877.

93. Tyagi $P$, Dixit U, Tyagi S, Jain A: Sedative effects of oral midazolam, intravenous midazolam and oral diazepam. J Clin Pediatr Dent 2012, 36:383-388

94. Patterson DR, Ptacek JT, Carrougher GJ, Sharar SR: Lorazepam as an adjunct to opioid analgesics in the treatment of burn pain. Pain 1997, 72:367-374.

95. Freeman EB, Köglmeier J, Martinez AE, Mellerio JE, Haynes L, Sebire NJ, Lindley KJ, Shah N: Gastrointestinal complications of epidermolysis bullosa in children. Br J Dermatol 2008, 158:1308-1314.

96. Fine JD, Mellerio JE: Extracutaneous manifestations and complications of inherited epidermolysis bullosa: part I. Epithelial associated tissues. J Am Acad Dermatol 2009, 61:367-384.

97. Travis SP, McGrath JA, Turnbull AJ, Schofield OM, Chan O, O'Connor AF, Mayou B, Eady RA, Thompson RP: Oral and gastrointestinal manifestations of epidermolysis bullosa. Lancet 1992, 340:1505-1506.

98. Ergun GA, Lin AN, Dannenberg AJ, Carter DM: Gastrointestinal manifestations of epidermolysis bullosa. A study of 101 patients. Medicine 1992, 71:121-127.

99. Marini I, Vecchiet F: Sucralfate: a help during oral management in patients with epidermolysis bullosa. J Periodontol 2001, 72:691-695.

100. Buchsel PC: Gelclair oral gel. Clin J Oncol Nurs 2003, 7:109-110.

101. Buchsel PC: Polyvinylpyrrolidone-sodium hyaluronate gel (Gelclair): a bioadherent oral gel for the treatment of oral mucositis and other painful oral lesions. Expert Opin Drug Metab Toxicol 2008, 4:1449-1454.

102. Cingi C, Songu M, Ural A, Yildirim M, Erdogmus N, Bal C: Effects of chlorhexidine/benzydamine mouth spray on pain and quality of life in acute viral pharyngitis: a prospective, randomized, double-blind, placebo-controlled, multicenter study. Ear Nose Throat J 2010, 89:546-549.

103. Vandenplas Y, Rudolph CD, Di Lorenzo C, Hassall E, Liptak G, Mazur L, Sondheimer J, Staiano A, Thomson M, Veereman-Wauters G, Wenzl TG, North American Society for Pediatric Gastroenterology Hepatology and
Nutrition, European Society for Pediatric Gastroenterology Hepatology and Nutrition: Pediatric gastroesophageal reflux clinical practice guidelines: joint recommendations of the North American Society for Pediatric Gastroenterology, Hepatology, and Nutrition (NASPGHAN) and the European Society for Pediatric Gastroenterology, Hepatology, and Nutrition (ESPGHAN). J Pediatr Gastroenterol Nutr 2009, 49:498-547.

104. Nwokediuko SC: Current trends in the management of gastroesophageal reflux disease: a review. ISRN Gastroenterol 2012, 2012:391631.

105. Fine JD, Johnson LB, Weiner M, Suchindran C: Gastrointestinal complications of inherited epidermolysis bullosa: cumulative experience of the National Epidermolysis Bullosa Registry. J Pediatr Gastroenterol Nutr 2008, 46:147-158.

106. Lai-Cheong JE, McGrath JA: What is Kindler syndrome? Skinmed 2011, 9:145-146.

107. Azizkhan RG, Stehr W, Cohen AP, Wittkugel E, Farrell MK, Lucky AW, Hammelman BD, Johnson ND, Racadio JM: Esophageal strictures in children with recessive dystrophic epidermolysis bullosa: an 11-year experience with fluoroscopically guided balloon dilatation. J Pediatr surg 2006, 41:55-60.

108. Anderson SH, Meenan J, Williams KN, Eady RA, Prinja H, Chappiti U, Doig L, Thompson RP: Efficacy and safety of endoscopic dilation of esophageal strictures in epidermolysis bullosa. Gastrointest Endosc 2004, 59:28-32.

109. Mortell AE, Azizkhan RG: Epidermolysis bullosa: management of esophageal strictures and enteric access by gastrostomy. Dermatol Clin 2010, 28:311-318.

110. Dohil R, Aceves SS, Dohil MA: Oral viscous budesonide therapy in children with epidermolysis bullosa and proximal esophageal strictures. J Pediatr Gastroenterol Nutr 2011, 52:776-777.

111. Hsieh CH, Huang CJ, Lin GT: Death from colonic disease in epidermolysis bullosa dystrophica. BMC Dermatol 2006, 6:2.

112. Belsey JD, Geraint M, Dixon TA: Systematic review and meta analysis: polyethylene glycol in adults with non-organic constipation. Int J Clin Pract 2010, 64:944-955.

113. Hanson S, Bansal N: The clinical effectiveness of Movicol in children with severe constipation: an outcome audit. Paediatr Nurs 2006, 18:24-28.

114. Shah N, Freeman E, Martinez A, Mellerio J, Smith W, Lindley KJ, Sebire NJ: Histopathological features of gastrointestinal mucosal biopsy specimens in children with epidermolysis bullosa. J Clin Pathol 2007, 60:843-844.

115. Gupta PJ, Heda PS, Shrirao SA, Kalaskar SS: Topical sucralfate treatment of anal fistulotomy wounds: a randomized placebo-controlled trial. Dis Colon Rectum 2011, 54:699-704.

116. Alpsoy $\mathrm{E}, \mathrm{Er} \mathrm{H}$, Durusoy C, Yilmaz $\mathrm{E}$ : The use of sucralfate suspension in the treatment of oral and genital ulceration of Behçet disease: a randomized, placebo-controlled, double-blind study. Arch Dermatol 1999, 135:529-532.

117. Nelson RL, Thomas K, Morgan J, Jones A: Non surgical therapy for anal fissure. Cochrane Database Syst Rev 2012, 2, CD003431.

118. Poh A, Tan KY, Seow-Choen F: Innovations in chronic anal fissure treatment: a systematic review. World J Gastrointest Surg 2010, 27:231-241.

119. Khan MT: Podiatric management in epidermolysis bullosa. Dermatol Clin 2010, 28:325-333.

120. Thastum M, Herlin T, Zachariae R: Relationship of pain-coping strategies and pain-specific beliefs to pain experience in children with juvenile idiopathic arthritis. Arthritis Rheum 2005, 53:178-184.

121. Terrill PJ, Mayou BJ, McKee PH, Eady RA: The surgical management of dystrophic epidermolysis bullosa (excluding the hand). Br J Plast Surg 1992, 45:426-434.

122. Maritsi D, Martinez AE, Mellerio JE, Eleftheriou D, Pilkington CA: An unusual case of epidermolysis bullosa complicated by persistent oligoarticular juvenile idiopathic arthritis; lessons to be learned. Pediatr Rheumatol Online J 2011, 9:13.

123. Gubinelli E, Angelo C, Pacifico V: A case of dystrophic epidermolysis bullosa improved with etanercept for concomitant psoriatic arthritis. Am J Clin Dermatol 2010, 11:53-54.

124. Fewtrell MS, Allgrove J, Gordon I, Brain C, Atherton D, Harper J, Mellerio JE, Martinez AE: Bone mineralization in children with epidermolysis bullosa. Br J Dermatol 2006, 154:959-962.

125. Martinez AE, Mellerio JE: Osteopenia and osteoporosis in epidermolysis bullosa. Dermatol Clin 2010, 28:353-355.

126. Bruckner AL, Bedocs LA, Keiser E, Tang JY, Doernbrack C, Arbuckle HA, Berman S, Kent K, Bachrach LK: Correlates of low bone mass in children 
with generalized forms of epidermolysis bullosa. J Am Acad Dermatol 2011, 65:1001-1009.

127. Lacativa PG, Farias ML: Osteoporosis and inflammation. Arq Bras Endocrinol Metabol 2010, 54:123-132.

128. Tilg H, Moschen AR, Kaser A, Pines A, Dotan I: Gut, inflammation and osteoporosis: basic and clinical concepts. Gut 2008, 57:684-694.

129. Levis S, Theodore G: Summary of AHRQ's comparative effectiveness review of treatment to prevent fractures in men and women with low bone density or osteoporosis: update of the 2007 report. J Manag Care Pharm 2012, 18:S1-15. discussion S13.

130. Noguera A, Ros JB, Pavía C, Alcover E, Valls C, Villaronga M, González E: Bisphosphonates, a new treatment for glucocorticoid-induced osteoporosis in children. J Pediatr Endocrinol Metab 2003, 16:529-536.

131. Gandrud LM, Cheung JC, Daniels MW, Bachrach LK: Low-dose intravenous pamidronate reduces fractures in childhood osteoporosis. J Pediatr Endocrinol Metab 2003, 16:887-892.

132. Falcini F, Trapani S, Ermini M, Brandi ML: Intravenous administration of alendronate counteracts the in vivo effects of glucocorticoids on bone remodeling. Calcif Tissue Int 1996, 58:166-169.

133. Chou R, Qaseem A, Snow V, Casey D, Cross JT Jr, Shekelle P, Owens DK, Clinical Efficacy Assessment Subcommittee of the American College of Physicians, American College of Physicians, American Pain Society Low Back Pain Guidelines Panel: Diagnosis and treatment of low back pain: a joint clinical practice guideline from the American College of Physicians and the American Pain Society. Ann Intern Med 2007, 147:478-491.

134. Fine JD, Johnson LB, Weiner M, Stein A, Cash S, Deleoz J, Devries DT, Suchindran C: Eye involvement in inherited epidermolysis bullosa: experience of the National Epidermolysis Bullosa Registry. Am J Ophthalmol 2004 138:254-262.

135. Figueira EC, Murrell DF, Coroneo MT: Ophthalmic involvement in inherited epidermolysis bullosa. Dermatol Clin 2010, 28:143-152.

136. Watson SL, Lee MH, Barker NH: Interventions for recurrent corneal erosions. Cochrane Database Syst Rev 2012, 9, CD001861.

137. Turner A, Rabiu M: Patching for corneal abrasion. Cochrane Database Syst Rev 2006, 2, CD004764.

138. Calder LA, Balasubramanian S, Fergusson D: Topical nonsteroidal anti-inflammatory drugs for corneal abrasions: meta-analysis of randomized trials. Acad Emerg Med 2005, 12:467-473.

139. Gibbins S, Stevens BJ, Yamada J, Dionne K, Campbell-Yeo M, Lee G, Caddell K, Johnston C, Taddio A: Validation of the Premature Infant Pain Profile-Revised (PIPP-R). Early Hum Dev 2014, 90:189-193.

140. Stevens BJ, Gibbins S, Yamada J, Dionne K, Lee G, Johnston C, Taddio A: The Premature Infant Pain Profile-Revised (PIPP-R): initial validation and feasibility. Clin J Pain 2014, 2014:238-243.

141. Hummel P, Puchalski M, Creech SD, Weiss MG: Clinical reliability and validity of the N-PASS: neonatal pain, agitation and sedation scale with prolonged pain. J Perinatol 2008, 28:55-60.

142. Krechel SW, Bildner J: CRIES: a new neonatal postoperative pain measurement score. Initial testing of validity and reliability. Paediatr Anaesth 1995, 5:53-61.

143. Lawrence J, Alcock D, McGrath P, Kay J, MacMurray SB, Dulberg C: The development of a tool to assess neonatal pain. Neonatal Netw 1993, 12:59-66.

144. Manworren RC, Hynan LS: Clinical validation of FLACC: preverbal patient pain scale. Pediatr Nurs 2003, 29:140-146

145. Gill AM, Cousins A, Nunn AJ, Choonara IA: Opiate-induced respiratory depression in pediatric patients. Ann Pharmacother 1996, 30:125-129.

146. Purcell-Jones G, Dormon F, Sumner E: The use of opioids in neonates. A retrospective study of 933 cases. Anaesthesia 1987, 42:1316-1320.

147. Lynn AM, Slattery JT: Morphine pharmacokinetics in early infancy. Anesthesiology 1987, 66:136-139.

148. Kart T, Christrup LL, Rasmussen M: Recommended use of morphine in neonates, infants and children based on a literature review: part 1-pharmacokinetics. Paediatr Anaesth 1997, 7:5-11.

149. Yamada J, Stinson J, Lamba J, Dickson A, McGrath PJ, Stevens B: A review of systematic reviews on pain interventions in hospitalized infants. Pain Res Manag 2008, 13:413-420.

150. Harrison D, Stevens B, Bueno M, Yamada J, Adams-Webber T, Beyene J, Ohlsson A: Efficacy of sweet solutions for analgesia in infants between 1 and 12 months of age: a systematic review. Arch Dis Child 2010, 95:406-413.
151. Cignacco EL, Sellam G, Stoffel L, Gerull R, Nelle M, Anand KJ, Engberg S: Oral sucrose and "facilitated tucking" for repeated pain relief in preterms: a randomized controlled trial. Pediatrics 2012, 129:299-308.

152. Mellerio JE, Weiner M, Denyer JE, Pillay El, Lucky AW, Bruckner A, Palisson F: Medical management of epidermolysis bullosa: Proceedings of the IInd International Symposium of Epidermolysis Bullosa, Santiago, Chile, 2005. Int J Dermatol 2007, 46:795-800.

153. Tremlett M, Anderson BJ, Wolf A: Pro-con debate: is codeine a drug that still has a useful role in pediatric practice? Paediatr Anaesth 2010, 20:183-194.

154. MacDonald N, MacLeod SM: Has the time come to phase out codeine? CMAJ 2010, 182:1825.

155. Allegaert K, Naulaers G: Gabapentin as part of multimodal analgesia in a newborn with epidermolysis bullosa. Paediatr Anaesth 2010, 20:972-973.

156. Saroyan JM, Tresgallo ME, Farkouh C, Morel KD, Schecter WS: The use of oral ketamine for analgesia with dressing change in an infant with epidermolysis bullosa: report of a case. Paediatr Dermato/ 2009 26:764-766

157. Jevtovic-Todorovic $\mathrm{V}$ : Anesthesia and the developing brain: are we getting closer to understanding the truth? Curr Opin Anaesthesiol 2011 24:395-399.

158. Fine JD, Johnson LB, Weiner M, Suchindran C: Cause-specific risks of childhood death in epidermolysis bullosa. J Pediatr 2008, 152:276-280.

159. Yuen WY, Duipmans JC, Molenbuur B, Herpertz I, Mandema JM, Jonkman MF: Long-term follow-up of patient with Herlitz-type junctional epidermolysis bullosa. Br J Dermatol 2012, 167:374-382.

160. Kho YC, Rhodes LM, Robertson SJ, Su J, Varigos G, Robertson I, Hogan P, Orchard D, Murrell DF: Epidemiology of epidermolysis bullosa in the antipodes: the Australasian epidermolysis bullosa registry with a focus on Herlitz junctional epidermolysis bullosa. Arch Dermatol 2010, 146:635-640.

161. Fine JD, Johnson LB, Weiner M, Li KP, Suchindran C: Epidermolysis bullosa and the risk of life-threatening cancers: the National EB Registry experience, 1986-2006. J Am Acad Dermatol 2009, 60:203-211.

162. Fine JD, Johnson LB, Weiner M, Stein A, Cash S, DeLeoz J, Devries DT, Suchindran C: Inherited epidermolysis bullosa and the risk of death from renal disease: experience of the National Epidermolysis Bullosa Registry. Am J Kidney Dis 2004, 44:651-660.

163. Fine JD, Hall M, Weiner M, Li KP, Suchindran C: The risk of cardiomyopathy in inherited epidermolysis bullosa. Br J Dermatol 2008, 159:677-682.

164. Fine JD, Johnson LB, Weiner M, Suchindran C: Tracheolaryngeal complications of inherited epidermolysis bullosa: cumulative experience of the National Epidermolysis Bullosa Registry. Laryngoscope 2007, 117:1652-1660.

165. Craig F, Abu-Saad Huijer H, Benini F, Kuttner L, Wood C, Feraris PC, Zernikow B: IMPaCCT: standards of paediatric palliative care. Eur J Pall Care 2007 14:1-7.

166. American Academy of Pediatrics. Committee on Bioethics and Committee on Hospital Care: Palliative care for children. Pediatrics 2000, 106:351-357.

167. World Health Organization Definition of Palliative Care. Available at: http://www.who.int/cancer/palliative/definition/en/

168. Mallipeddi R: Epidermolysis bullosa and cancer. Clin Exp Dermatol 2002, 27:616-623

169. World Health Organization: WHO Guidelines on the Pharmacological Treatment of Persisting Pain in Children with Medical IIInesses. Geneva, Switzerland: WHO Press, World Health Organization; 2012.

170. Mercadante S: Opioid titration in cancer pain: a critical review. Eur J Pain 2007, 11:823-830.

171. Bruera E, Pereira J, Watanabe S, Belzile M, Kuehn N, Hanson J: Opioid rotation in patients with cancer pain: a retrospective comparison of dose ratios between methadone, hydromorphone, and morphine. Cancer 1996, 78:852-857.

172. Quigley C: Opioid switching to improve pain relief and drug tolerability. Cochrane Database Syst Rev 2004, 3, CD004847.

173. Gagnon B, Almahrezi A, Schreier G: Methadone in the treatment of neuropathic pain. Pain Res Manag 2003, 8:149-154.

174. McNicol ED, Carr DB, Eisenberg E: Opioids for neuropathic pain. Cochrane Database Syst Rev 2006, 8, CD006146.

175. Clements JA, Nimmo WS, Grant IS: Bioavailability, pharmacokinetics and analgesic activity of ketamine in humans. J Pharm Sci 1982 71:539-542 
176. O'Neil B, Lucas C, Gannon C: Use of a subcutaneous syringe driver in epidermolysis bullosa. Palliat Med 2001, 15:77-78.

177. Elsner F, Radbruch L, Loick G, Gaertner J, Sabatowski R: Intravenous versus subcutaneous morphine titration in patients with persisting exacerbation of cancer pain. J Palliat Med 2005, 8:743-750.

178. Reymond L, Charles MA, Bowman J, Treston P: The effect of dexamethasone on the longevity of syringe driver subcutaneous sites in palliative care patients. Med J Aust 2003, 178:486-489.

179. Association of Paediatric Palliative Medicine: Master Formulary. Available at: http//wwww.appm.org.uk/resources/APPM_Master_Formulany_2012__2nd_ edition.pdf.

180. Mercadante S, Intravaia G, Villari P, Ferrera P, Riina S, Mangione S: Intravenous morphine for breakthrough (episodic-) pain in an acute palliative care unit: a confirmatory study. J Pain Symptom Manage 2008, 35:307-313.

181. Mercadante S, Villari P, Ferrera P, Mangione S, Casuccio A: The use of opioids for breakthrough pain in acute palliative care unit by using doses proportional to opioid basal regimen. Clin J Pain 2010, 26:306-309.

182. Zeppetella G, Davies AN: Opioids for the management of breakthrough (episodic) pain in cancer patients. Cochrane Database Syst Rev 2013, 10, CD004311.

183. Nischler E, Diem A: Pruritis in epidermolysis bullosa. In Life with Epidermolysis Bullosa: Etiology, Diagnosis, Multidisciplinary Care and Therapy. Edited by Fine JD, Hinter H. Austria: Springer-Verlag/Wein; 2008:233-240.

184. Jeffry J, Seungil K, Chen ZF: Itch signalling in the nervous system. Physiology 2011, 26:286-292.

185. Raap U, Stander S, Metz M: Pathophysiology of itch and new treatments. Curr Opin Allergy Clin Immunol 2011, 11:420-427.

186. Goutos I, Eldardiri M, Khan AA, Dziewulski P, Richardson PM: Comparative evaluation of antipruritic protocols in acute burns. The emerging value of gabapentin in the treatment of burns pruritis. J Burn Res 2010, 31:57-63.

187. EB Nurse. Itching [http://www.ebnurse.org/index.php?id=64]

188. Ahuja RB, Gupta R, Gupta G, Shrivastava P: A comparative analysis of cetirizine, gabapentin and their combination in the relief of post-burn pruritus. Burns 2011, 37:203-207.

189. Hundley JL, Yosipovitch G: Mirtazapine for reducing nocturnal itch in patients with chronic pruritus: a pilot study. J Am Acad Dermatol 2004, 50:889-891.

190. Davis MP, Frandsen JL, Walsh D, Andresen S, Taylor S: Mirtazapine for pruritus. J Pain Symptom Manage 2003, 25:288-291.

191. Shaw RJ, Dayal S, Good J, Bruckner AL, Joshi SV: Psychiatric medications for the treatment of pruritis. Psychosom Med 2007, 69:970-978.

192. Zylicz Z, Krainik M: Serotonin reuptake inhibitors and other antidepressants in the treatment of chronic pruritus. Pruritus 2010, 3:301-306.

193. Calikoglu E, Anadolu R: Management of generalized pruritus in dominant dystrophic epidermolysis bullosa using low-dose oral cyclosporin. Acta Derm Venereol 2002, 82:380-382.

194. Jones EA: Pruritus and fatigue associated with liver disease: is there a role for ondansetron? Expert Opin Pharmacother 2008, 9:645-651.

195. Deshpande PV: Ondansetron for paediatric uraemic pruritus: a case report. Pediatr Nephrol 2004, 19:694-696.

196. Murphy M, Reaich D, Pai P, Finn P, Carmichael AJ: A randomized, placebo-controlled, double-blind trial of ondansetron in renal itch. Br J Dermatol 2003, 148:314-317.

197. Tey HL, Yosipovitch G: Targeted treatment of pruritus: a look into the future. Br J Dermatol 2011, 165:5-17.

198. Ahuja RB, Gupta GK: A four arm, double blind, randomized and placebo controlled study of pregabalin in the management of post-burn pruritus. Burns 2013, 39:24-29.

doi:10.1186/s12916-014-0178-2

Cite this article as: Goldschneider et al:: Pain care for patients with epidermolysis bullosa: best care practice guidelines. BMC Medicine 2014 12:178.

\section{Submit your next manuscript to BioMed Central and take full advantage of:}

- Convenient online submission

- Thorough peer review

- No space constraints or color figure charges

- Immediate publication on acceptance

- Inclusion in PubMed, CAS, Scopus and Google Scholar

- Research which is freely available for redistribution 